\title{
Brightness and Uniformity Perception of Virtual Corridor with Artificial Lighting Systems
}

\author{
Piotr Pracki *(D) and Rafał Krupiński *(D) \\ Lighting Technology Division, Electrical Power Engineering Institute, Warsaw University of Technology, \\ 75 Koszykowa St., 00-662 Warsaw, Poland \\ * Correspondence: piotr.pracki@ien.pw.edu.pl (P.P.); rafal.krupinski@ien.pw.edu.pl (R.K.)
}

check for updates

Citation: Pracki, P.; Krupiński, R.

Brightness and Uniformity

Perception of Virtual Corridor with Artificial Lighting Systems. Energies 2021, 14, 412. https://doi.org/ 10.3390/en14020412

Received: 30 November 2020 Accepted: 8 January 2021 Published: 13 January 2021

Publisher's Note: MDPI stays neutral with regard to jurisdictional clai$\mathrm{ms}$ in published maps and institutional affiliations.

Copyright: $(\odot 2021$ by the authors. Licensee MDPI, Basel, Switzerland. This article is an open access article distributed under the terms and conditions of the Creative Commons Attribution (CC BY) license (https:// creativecommons.org/licenses/by/ $4.0 /)$.

\begin{abstract}
This article compares the brightness and uniformity perception of virtual corridor displayed on computer screens and under different surrounding conditions, between two groups of respondents. The computer simulations of 10 lighting scenarios in the empty corridor, diverse in terms of luminance distribution and lighting power density, were developed. The visual assessment of the lighting effects was carried out on the basis of surveys. The respondents assessed the brightness and uniformity of each plane and entire corridor for each scenario, using semantic differential scaling. Each person from the first group individually made their evaluations on the same computer screen placed in the experimental box. Each person from the second group made the assessments on different computer screens, and all respondents from this group made the evaluations in the computer room at the same time. A high convergence of the results between the groups was found in the assessments of brightness and uniformity perception for consecutive lighting situations. In $93.75 \%$ of cases, the same perception in brightness and uniformity between the group means was achieved. A high convergence of the results between the groups in the assessment of brightness and uniformity perception for the same lighting situations was also demonstrated.
\end{abstract}

Keywords: lighting technology; interior lighting; simulation; survey; perception

\section{Introduction}

A selection of any interior lighting solution is based on a number of lighting and non-lighting criteria, both objective and subjective. The objective assessment of the interior lighting is usually based on checking if it meets the requirements for photometric parameters, e.g., [1,2] The objective assessment of non-lighting parameters may concern: Energy efficiency, e.g., [3,4], environmental impact, e.g., [5,6], or lighting cost, e.g., [7,8]. The basic subjective assessment of lighting is a visual evaluation and directly applies to the lighting effects connected to the brightness distribution in the interior, e.g., [9,10]. The psychological impact of the interior luminous environment can also be assessed, e.g., [11,12], including some aesthetic aspects, e.g., [13,14].

The appraisal of lighting effects is carried out in the illuminated space, in real rooms, e.g., [15,16], arranged rooms [17] or stands [18], as well as in lightboxes, e.g., [19,20]. The assessment of lighting effects is carried out on the basis of images of the illuminated interiors: photos of real interiors [21] or visualizations of virtual interiors [22]. Images of the illuminated interiors can be presented on projection screens [23] or display screens [24].

Undoubtedly, the presentation of virtual images of the illuminated interior on the computer screen is still the most commonly used form of showing lighting effects for visual evaluation in practice. This arises from the fact of using this method in the design process. Most often such an appraisal is made at the lighting design stages. The computer visualizations of room illumination developed by the design team are used to discuss and verify the lighting concept, and to present the final lighting solutions. The lighting effects in the rooms are presented on computer screens of the people from the project team and 
the customers, i.e., the people making decisions on choosing the final solution, including the investors and the future users. In practice, therefore, lighting effects are assessed on different and usually uncalibrated computer screens. The use of such an evaluation has many limitations and should only be used as a supplementary criterion. However, as a result of the widespread use of computers and their continuous development, we should strive for a better use of this method when making decisions on the choice of lighting solution. The question also arises if different people similarly assess the lighting effects in the virtual rooms presented on different computer screens and under different surrounding conditions.

A significant part of the research on assessing the opportunity to use the computer lighting images in virtual rooms focuses on examining whether and to what extent there is a convergence of subjective evaluation of lighting in a real and virtual room. One of the first studies in this area was carried out by A. Mahdavi and H. Eissa [25]. In their research, two groups of participants evaluated five lighting situations in office-type rooms. The first group assessed the illumination in the real rooms from the specific observation directions. The second group assessed the illumination of the same lighting situations on the basis of the virtual visualizations generated in the Lightscape software and presented on a 19-inch computer monitor. Ten impressions between these groups were compared with the use of seven-point semantic scales, following the methodology used in [26]. The results suggested that "such images could reliably represent certain aspects of the lighting conditions in real spaces. The overall correlation between the image-based and spacebased evaluations was found to be significant" [25].

In the research done by G. Newsham et al. [27] the group of respondents evaluated six lighting situations in the rooms of various purposes. These situations were assessed in the real rooms and based on the room images presented on a 17-inch computer monitor in both conventional and HDR mode. All images were taken with a Canon EOS Digital Rebel XT camera. Impressions on brightness, uniformity, pleasantness, and glare were compared in the group with the use of continuous semantic scales, following the methodology applied in [28]. The results suggested that "for evaluations of visual appearance of interior scenes featuring large areas of high luminance, the HDR method may be used as a surrogate for experiencing a real space both for lighting quality research, and in the design process" [27].

In the research by C. Villa and R. Labayrade [29], a web application was developed to investigate online-based psycho-visual experiments. The visual assessment of the lighting effects was based on 26 images of virtual lighting situations in the office room. First, the lighting effects were evaluated by a control group of 30 people, initially under laboratory conditions (on the stereoscopic display device with dimensions of $1.69 \mathrm{~m} \times 1.26 \mathrm{~m}$ and resolution of $1024 \times 768$ pixels) and then online on their own computers. The results revealed no statistically significant differences between data collected in the laboratory and online. Then, an online-based experiment involving 1114 observers was conducted to study the uncontrolled experimental conditions that may impact results. The results suggested that 100 observers were enough to remove bias, related mainly to the perceived contrast and brightness of the display and the brightness of the surrounding area. The images of virtual lighting situations were prepared on Autodesk 3ds MAX software. In these images, the lighting for task area-computer desk-was mainly exposed. Participants focused on a paper-based desk job evaluated each lighting scene on a scale from 0 (not at all) to 10 (extremely), answering the question about luminous environment suitability for office work.

In our research, we focused on a comparison between groups of general perception of lighting in a virtual room whose images were presented on the screens of commonly available computers. The main objective of the research was to determine the differences between two groups of respondents in the evaluation of brightness and uniformity perception of the virtual lit corridor presented on the computer screens. Additionally, we demonstrated the performed calculation-based assessment of the levels and the uniformity of 
illuminance in the corridor as well as the impact of the ceiling and wall lighting in the corridor on the lighting power density in the investigated cases.

The scope of research covered as follows:

- Developing the computer simulations of lighting in the virtual corridor, diverse in terms of the luminance distribution on the room planes.

- Analyzing and evaluating the lighting solutions in the corridor based on the calculation results of photometric parameters.

- Carrying out the qualitative analysis and assessment of the lighting solutions in the corridor presented on the computer screen based on the results of the survey.

\section{Methods}

The research concerned appraising the brightness and uniformity perception of a virtual lit interior model. The computer 3D corridor model was the object of the research. The choice of the corridor resulted from the common use of communication zones and the simplicity of this type of rooms. The accomplishment of the work goal was based on simulations and surveys. The research was done in two stages as follows:

- Developing the computer simulations of lighting solutions and carrying out the quantitative evaluation of illuminance distribution and lighting power density in the corridor.

- Conducting the surveys and assessing the brightness distribution perception based on the images of lighting solutions in the corridor presented on the computer screens.

At the first stage of research, the simulation tests were carried out. The computer model of the corridor was developed, and the simulations were performed for various lighting situations. The corridor was cuboidal and empty, $24 \mathrm{~m}$ long, $3 \mathrm{~m}$ wide, and $3 \mathrm{~m}$ high. The ceiling and walls were white, with reflectance of 0.7 , and the floor was grey, with reflectance of 0.3 . It was assumed that the reflection of the luminous flux inside had Lambertian characteristics and the impact of the spectral distribution of radiation was not considered.

The computer model of the corridor was created in Autodesk 3ds Max and DIALux. The illuminance and luminance distribution calculations were performed on each of the corridor planes in each program. The quantitative evaluation of lighting was made on the base of DIALux results. The corridor lighting visualizations were created in 3ds MAX. The images generated by $3 \mathrm{~d}$ s Max were controlled in terms of the luminance distribution. The brightness and uniformity assessments were made on the base of these images that were presented on computer screens.

In order to develop different luminance distributions in the corridor, six types of luminaires with different luminous intensity distributions were selected: Three direct lighting luminaires (A, B, and C), two direct-indirect lighting luminaires (D and E)., and one indirect lighting luminaire $(\mathrm{F})$. The luminous intensity polar curves of the luminaires are shown in Figure 1. 


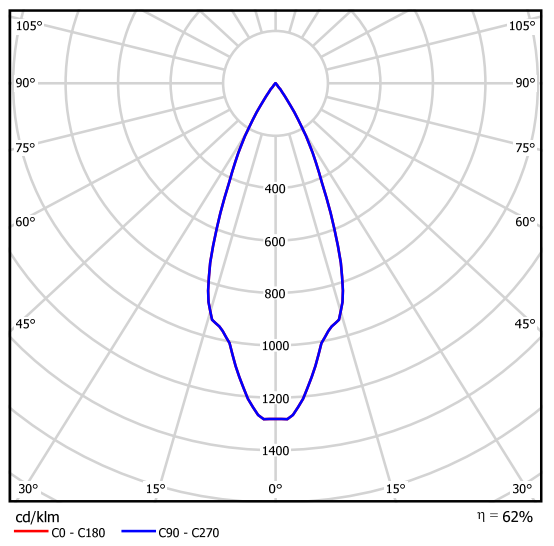

Luminaire (A)

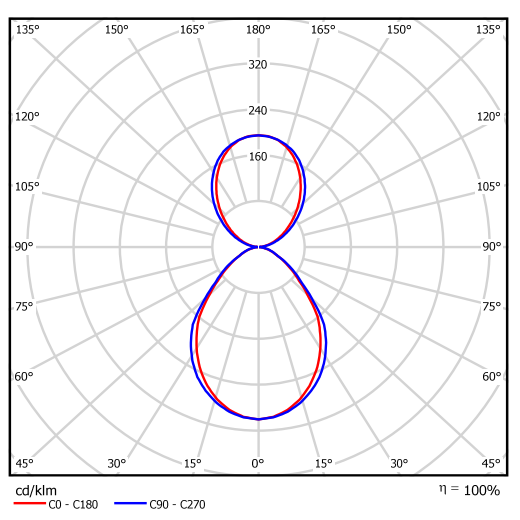

Luminaire (D)

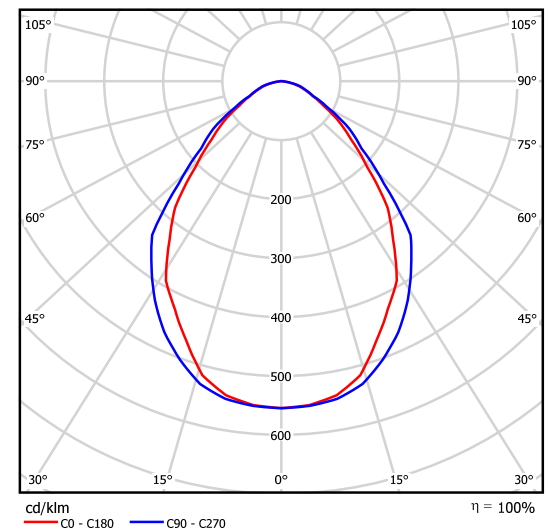

Luminaire (B)

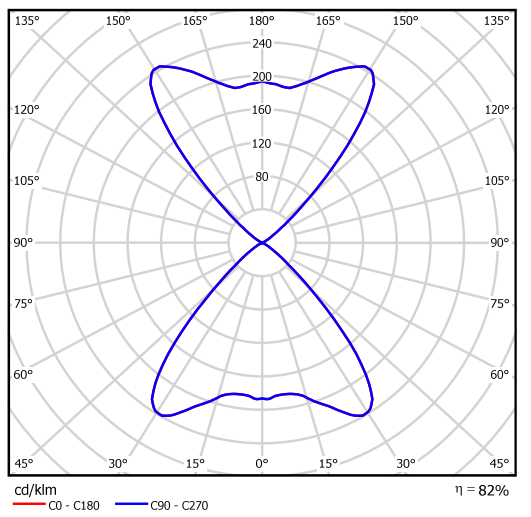

Luminaire (E)

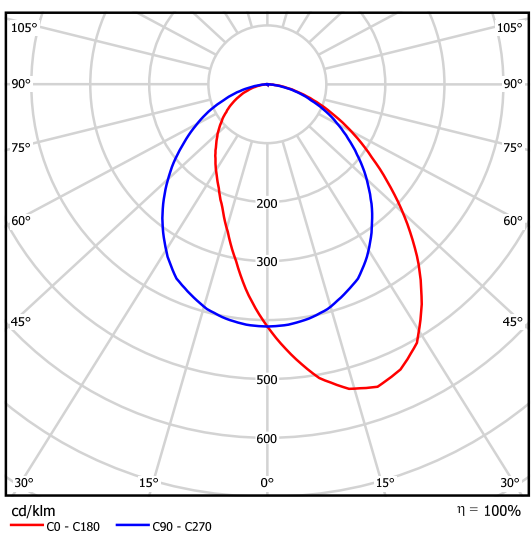

Luminaire $(\mathbf{C})$

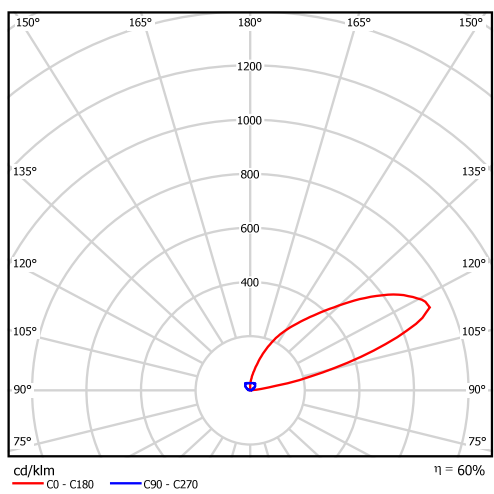

Luminaire (F)

Figure 1. Luminous intensity distribution curves of selected luminaires.

The general lighting in the corridor was considered. In each case, the level of the average maintained illuminance of $100 \mathrm{~lx}$ and lighting uniformity not lower than 0.4 were generated on the work plane. The necessity of meeting these requirements determined a number of the luminaires and their luminous flux as well as their layout. The symmetrical lighting of the corridor was taken into account in each case, i.e., the illumination of mutually parallel walls was identical. The calculations of the illuminance distribution for the work plane were made at the floor height, with the assumption of maintenance factor of 0.8 . As for the calculation of the utilization factor and the installed power density of the solutions, it was assumed that the light output ratio of luminaires was 0.8 , and the luminous efficacy of light sources was $150 \mathrm{~lm} \cdot \mathrm{W}^{-1}$ (the luminous efficacy of the luminaires was $120 \mathrm{~lm} \cdot \mathrm{W}^{-1}$ ). These values are fairly typical of LED technology and currently used luminaires. Ultimately, 10 computer lighting solutions were created for the corridor.

The following parameters were calculated in DIALux for each solution:

- $\mathrm{E}_{\mathrm{F}}$-the mean illuminance of the floor.

- $\mathrm{L}_{\mathrm{F}}$ - the mean luminance of the floor.

- $\mathrm{U}_{\mathrm{FMIN}}$ - the uniformity of illuminance/luminance of the floor.

- $\mathrm{E}_{\mathrm{W}}$-the mean illuminance of the walls.

- $\mathrm{L}_{W}$-the mean luminance of the walls.

- $\mathrm{U}_{\mathrm{WMIN}}$ - the uniformity of illuminance/luminance of the walls.

- $\mathrm{E}_{\mathrm{C}}$-the mean illuminance of the ceiling.

- $\quad \mathrm{L}_{\mathrm{C}}$-the mean luminance of the ceiling.

- $\mathrm{U}_{\mathrm{CMIN}}$ - the uniformity of illuminance/luminance of the ceiling.

- $\mathrm{L}_{\mathrm{R}}$ - the average luminance of the interior (the weighted average relative to the surface areas of the interior planes). 
- $\quad$ UF-the utilization factor.

- $\quad$ PD—the installed power density of lighting in the interior.

The quantitative evaluation of lighting consisted in checking the fulfillment of the requirements and recommendations regarding the average maintained illuminance and uniformity of lighting for the floor (work plane), ceiling, and walls [30]. They are shown in Table 1. The appraisal also involved a comparison between the solutions of the utilization factor and the installed power density. The impact of ceiling and wall lighting on these parameters was also demonstrated.

Table 1. Requirements and recommendations for lighting of the corridor planes.

\begin{tabular}{ccc}
\hline Par. & Requirement & Recommendation \\
\hline$E_{F}[1 \mathrm{~lx}]$ & 100 & - \\
$\mathrm{U}_{\text {FMIN }}[-]$ & 0.4 & - \\
$\mathrm{E}_{\mathrm{W}}[\mathrm{lx}]$ & 50 & 75 \\
$\mathrm{U}_{\text {WMIN }}[-]$ & 0.1 & - \\
$\mathrm{E}_{\mathrm{C}}[\mathrm{lx}]$ & 30 & 50 \\
$\mathrm{U}_{\text {CMIN }}[-]$ & 0.1 & - \\
\hline
\end{tabular}

At the second stage of research, the survey was conducted. Based on the developed questionnaire, the qualitative assessment of ceiling, wall, floor, and whole corridor illumination was performed for each solution. The respondents evaluated the brightness and uniformity of the individual lit planes and entire interior. The assessment was carried out on the basis of images of lighting visualization presented on the computer screens. The corridor lighting visualizations were created in Autodesk 3ds MAX.

The questionnaire used in the research included the respondents' personal data and the appraisal of the selected corridor lighting features. In terms of personal data, the survey covered as follows: The respondents' gender, age, education, and occupation as well as information about the state of their sight and well-being. Seven-point semantic differential scales were used to assess the selected lighting features. This methodology has been used many times in research on the perception of interior lighting [31]. The questionnaire included the evaluation of brightness and uniformity of the ceiling, wall, floor, and entire interior illumination. The part of the survey concerning the brightness and uniformity assessment of the floor illumination is presented in Figure 2. The same evaluation way concerned the brightness and uniformity perception assessment of the lit walls, floor, and entire corridor.

\begin{tabular}{|c|c|c|c|c|c|c|}
\hline \multicolumn{7}{|c|}{ Assess floor brightness and uniformity in the corridor } \\
\hline $\begin{array}{c}\text { Extremely } \\
\text { bright }\end{array}$ & $\begin{array}{c}\text { Very } \\
\text { bright }\end{array}$ & $\begin{array}{c}\text { Rather } \\
\text { bright }\end{array}$ & Moderate & $\begin{array}{c}\text { Rather } \\
\text { dim }\end{array}$ & $\begin{array}{c}\text { Very } \\
\operatorname{dim}\end{array}$ & $\begin{array}{c}\text { Extremely } \\
\text { dim }\end{array}$ \\
\hline $\begin{array}{c}\text { Extremely } \\
\text { uniform }\end{array}$ & $\begin{array}{c}\text { Very } \\
\text { uniform }\end{array}$ & $\begin{array}{c}\text { Rather } \\
\text { uniform }\end{array}$ & Moderate & $\begin{array}{c}\text { Rather } \\
\text { non-uniform }\end{array}$ & $\begin{array}{c}\text { Very } \\
\text { non-uniform }\end{array}$ & $\begin{array}{c}\text { Extremely } \\
\text { non-uniform }\end{array}$ \\
\hline
\end{tabular}

Figure 2. Part of questionnaire concerning the assessment of floor brightness and uniformity illumination in the corridor.

The survey was conducted according to the following procedure:

- Discussing the objective of the research, the questionnaire content, and completion order.

- Receiving the consent from the respondents to take part in the survey.

- Starting the survey.

- Taking a place in front of the computer screen by the respondent.

- Handing over the first part of the personal data survey. 
- Completing the first part of the questionnaire by the respondents.

- Collecting the first part of the survey.

- Displaying the lighting visualization, variant 1 on the computer screens.

- Handing over the second part of the questionnaire concerning the assessment of lighting features in variant 1 .

- Completing the second part of the questionnaire by the respondents.

- Collecting the second part of the survey.

- Repeating the procedure for the second part of the survey, for variants from 2 to 10.

- Ending the survey and thanking the participants for taking part in the research.

Two groups of students from the Electrical Power Engineering Institute, Lighting Technology Division, Warsaw University of Technology, participated in the research. The respondents had basic knowledge of lighting technology and had not participated in similar studies yet.

Every surveyed group consisted of 10 people ( 5 women and 5 men in each group). All respondents were in the age group of 19-25 years. All respondents took part in the entire survey and completed all parts of the questionnaire.

The first group (Group B-from "Box") participated in the research that was carried out in a box adapted for this purpose at the Lighting Technology Division, Warsaw University of Technology. There was a computer station in the box. The recessed ceiling luminaires were used for the electric lighting in the box. The luminous fluxes of the light sources were adjusted to produce the level of average luminance on the wall behind the screen (in the respondents' field of view) of approximately $10 \mathrm{~cd} \cdot \mathrm{m}^{-2}$. The luminance distributions of computer screens for the individual variants were also measured. Therefore, the lighting conditions were alike to all respondents and were controlled. Each of the respondents from this group took part in the survey individually.

The second group (Group C-from "Classroom") participated in the research that was carried out in the computer room of the Lighting Technology Division, Warsaw University of Technology. The available daylight, which came through the windows located on the northern wall of the room, was used to illuminate the interior. The windows were covered with louvers to reduce the luminance of the windows and to eliminate the view-out. The incoming daylight was sufficient to read the information and fill in the questionnaires. The lighting conditions in the room were quite similar for all respondents but were not controlled. All respondents in Group $C$ used the same types of computer screens (different from the one applied by the respondents in Group B) that were not calibrated. All participants from this group took part in the survey at the same time. Figure 3 shows the venues where the research was done.

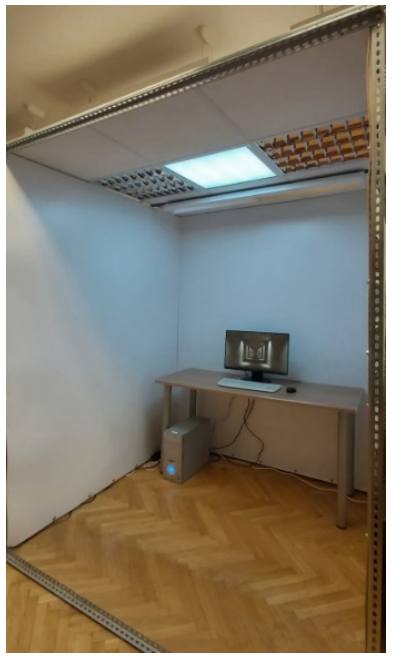

(a)

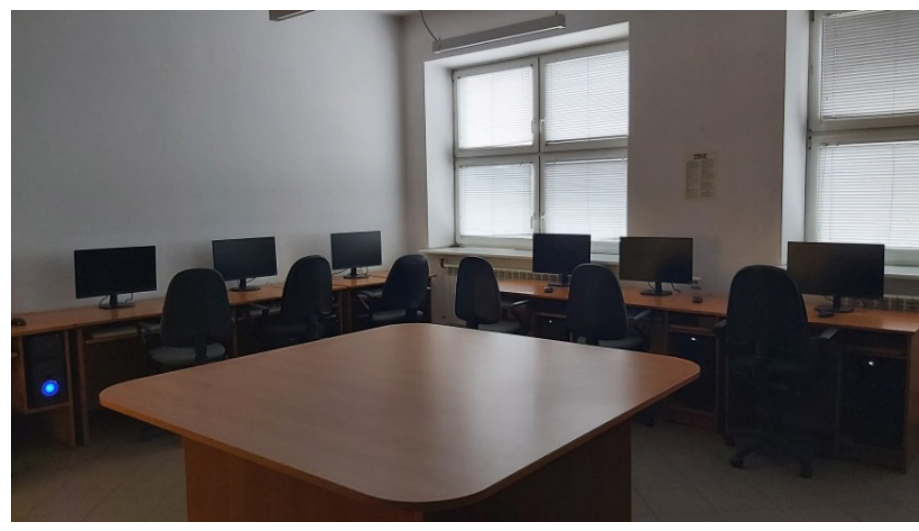

(b)

Figure 3. Experimental conditions for group: B (Box) (a) and C (Classroom) (b). 
The survey results considering brightness and uniformity perception were processed into numerical values. Value 1 was assigned to extremely dim/extremely non-uniform answers. Value 7 was assigned to extremely bright/extremely uniform answers. Values from 2 to 6 were assigned to intermediate answers, relatively to the impression intensity. For every lighting situation and for each group separately, the mean values of perceived brightness and uniformity were calculated for every plane and the entire corridor.

The qualitative evaluation of lighting was comparative and applied to:

- The convergence in assessment of changes in the brightness and uniformity perception for successive lighting situations between the groups.

- The convergence of brightness and uniformity perception for a given lighting situation between the groups.

\section{Results and Discussion}

3.1. The Computer Simulation and Quantitative Assessment of Lighting

As a result of the first stage of the research, the computer simulations of lighting were developed. Each of 10 solutions elaborated was briefly presented in the following way: The used means and obtained effects.

Lighting variant 1 (Figure 4) was performed with the use of eight A-type luminaires located directly on the ceiling, in one row along the corridor. The lighting installation was characterized by the lowest mean illuminances of the ceiling and walls among all variants.

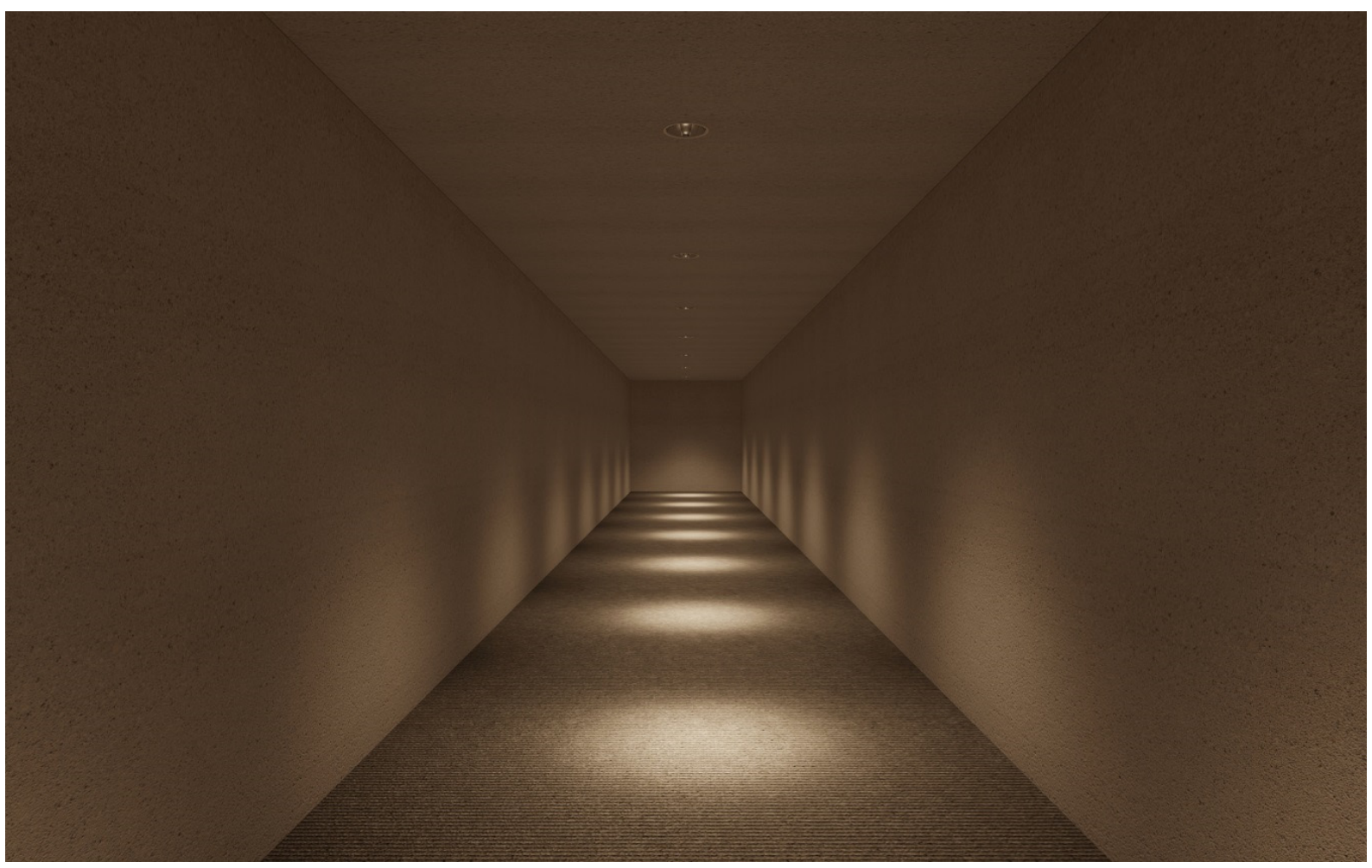

Figure 4. Computer simulation of corridor lighting for variant 1.

Lighting variant 2 (Figure 5) was implemented using 16 A-type luminaires (with a lower luminous flux than in variant 1) located directly on the ceiling, in two rows along the corridor. Placing the luminaires near the walls caused a significant increase in mean illuminance and a reduction in uniformity of the walls compared to variant 1. 


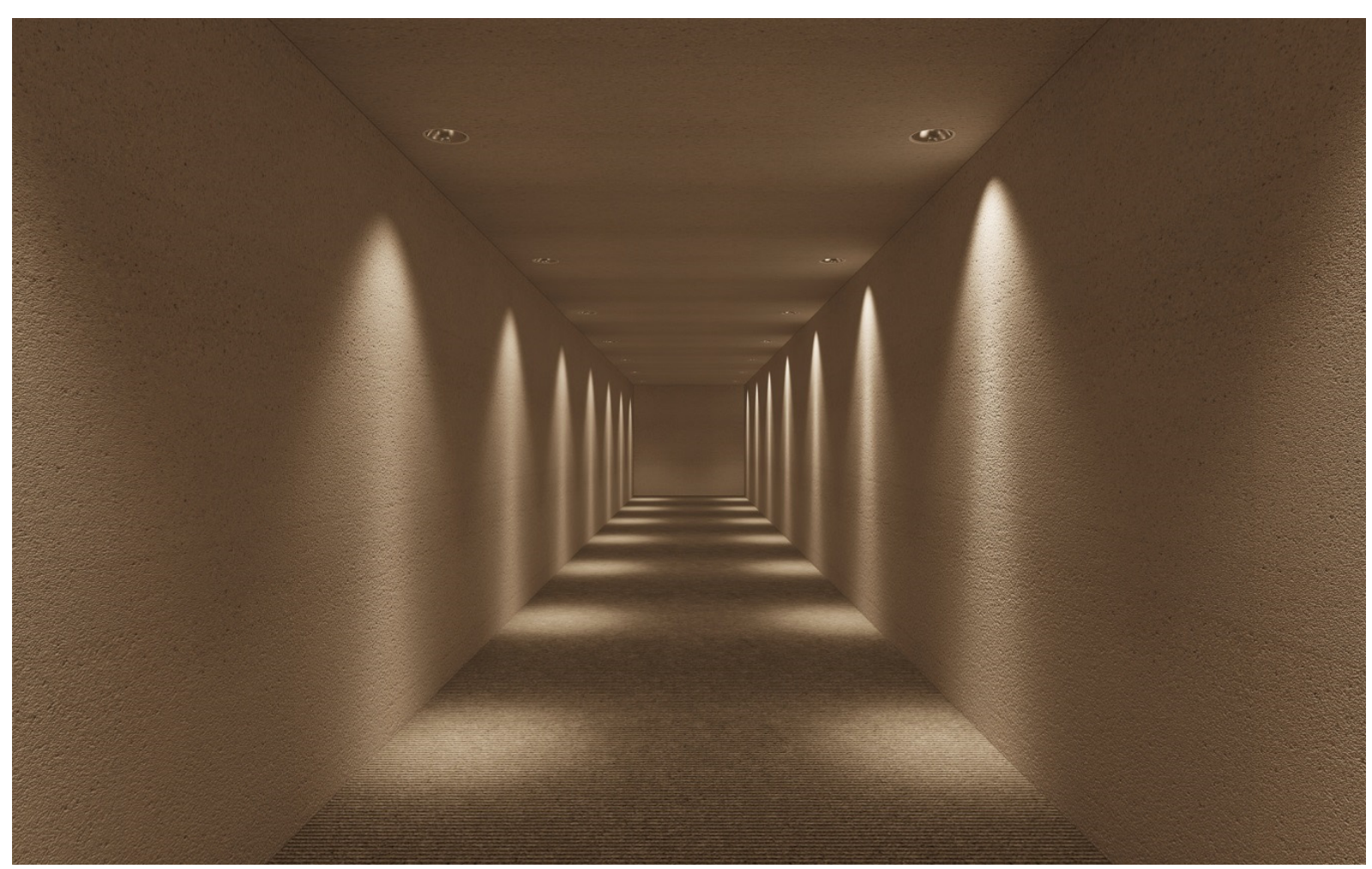

Figure 5. Computer simulation of corridor lighting for variant 2.

Lighting variant 3 (Figure 6) was performed with the use of 22 B-type luminaires located directly on the ceiling, in one continuous line along the corridor. The effect of uniform illumination of the walls was achieved. The mean illuminance on the walls was similar to that of variant 2.

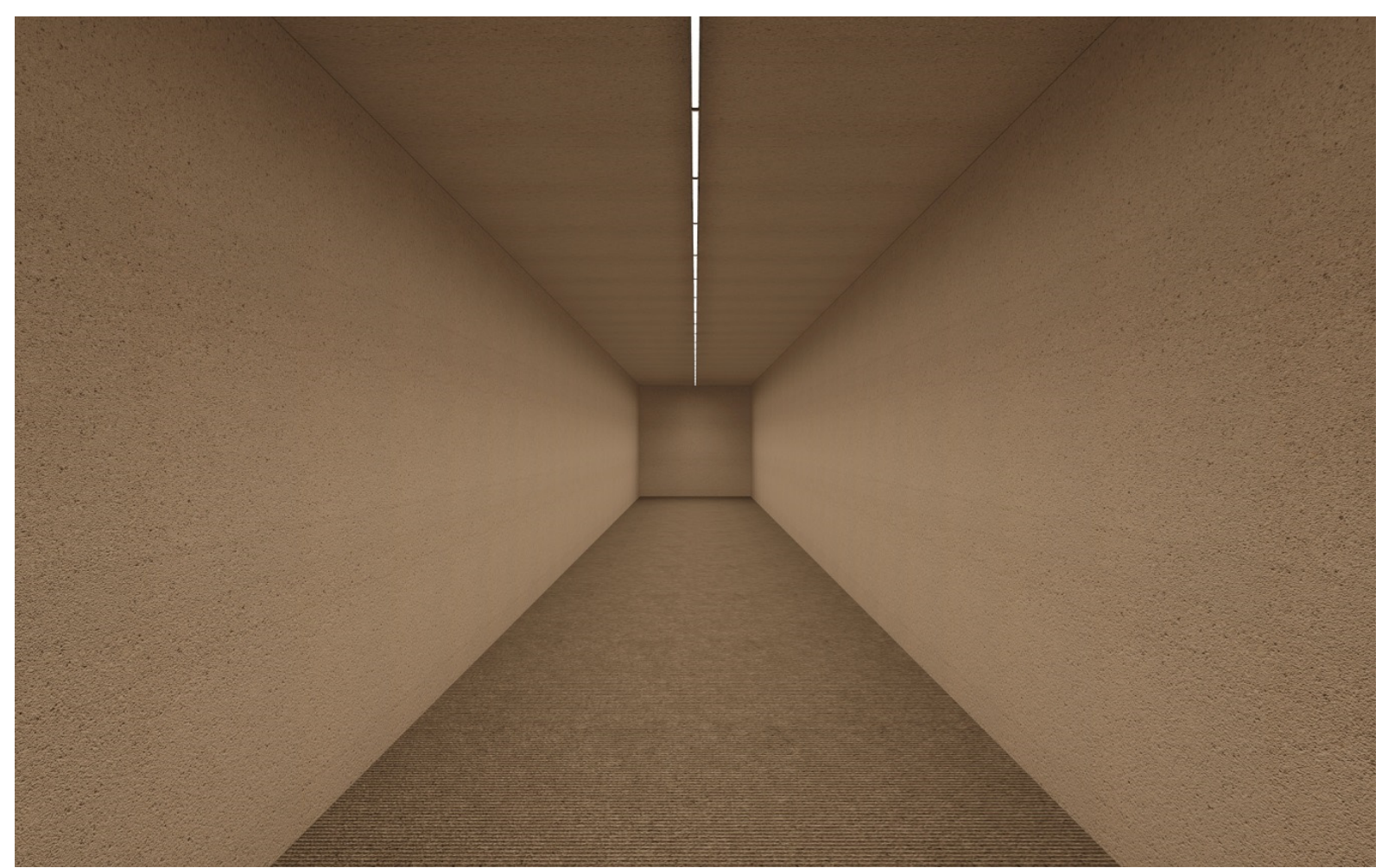

Figure 6. Computer simulation of corridor lighting for variant 3. 
Lighting variant 4 (Figure 7) was implemented with the use of 6 B-type luminaires (with a higher luminous flux than in variant 3 ) located directly on the ceiling, in one noncontinuous line along the corridor. The use of the non-continuous light line reduced the wall illumination uniformity compared to variant 3 while maintaining the mean illuminance value.

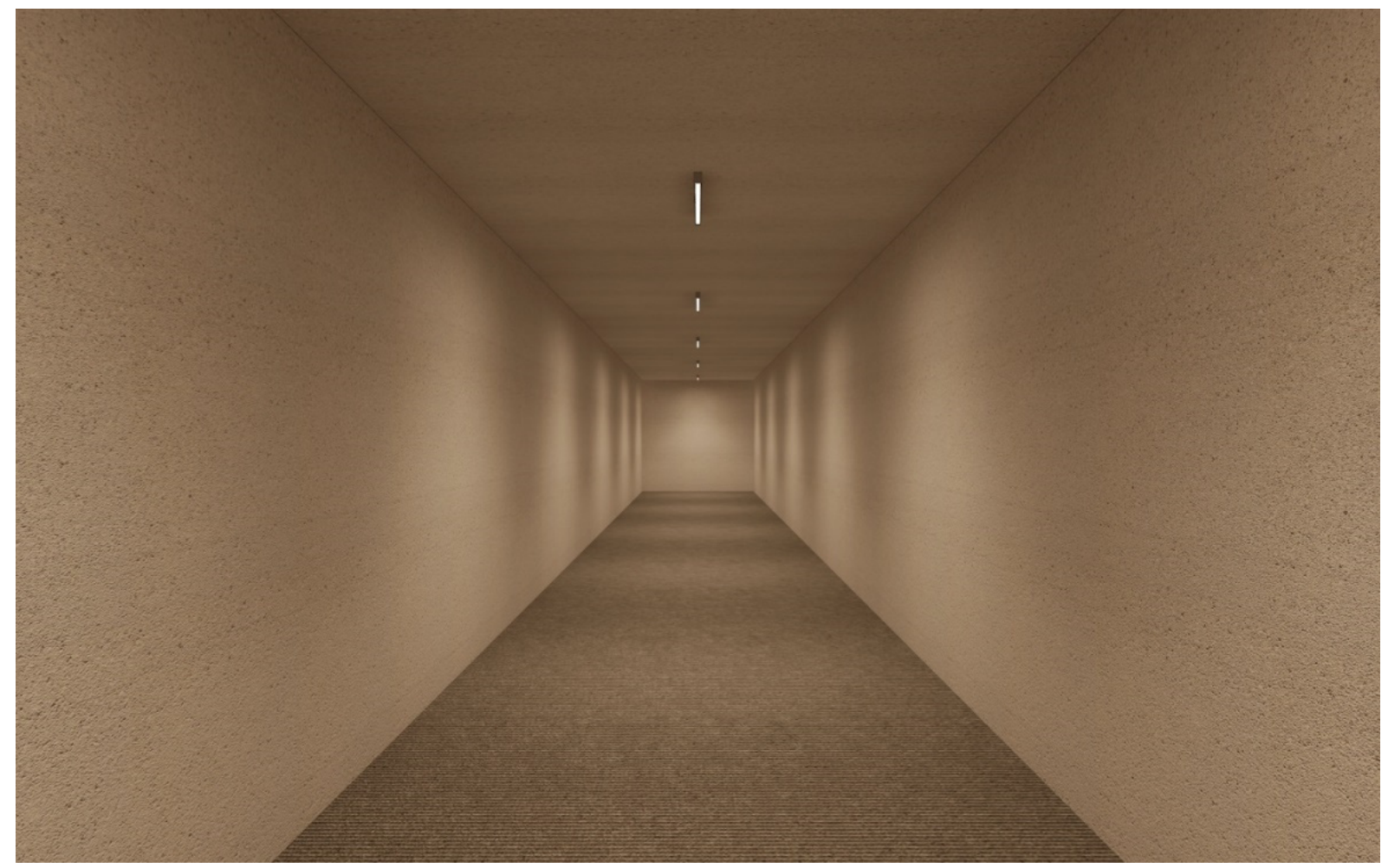

Figure 7. Computer simulation of corridor lighting for variant 4 .

Lighting variant 5 (Figure 8) was performed using 44 C-type luminaires located directly on the ceiling, in two continuous lines along the corridor. The asymmetric light distribution of the luminaires and the proximity of the walls caused a significant rise in mean illuminance of the wall. At the same time, the longitudinal uniformity of the walls was high.

Lighting variant 6 (Figure 9) was performed with the use of 12 C-type luminaires (with a higher luminous flux than in variant 5) located directly on the ceiling, in two non-continuous lines along the corridor. The use of the non-continuous light lines lowered the wall illumination uniformity compared to variant 5 while maintaining the average illuminance value

Lighting variant 7 (Figure 10) was implemented using 18 D-type luminaires suspended from the ceiling, in one continuous line along the corridor. The luminous flux sent into the upper hemisphere caused a significant increase in the mean ceiling illuminance. The longitudinal ceiling illumination uniformity was high and the transverse one was low. The average illuminance and uniformity on the wall were comparable to variant 3.

Lighting variant 8 (Figure 11) was performed with the use 6 D-type luminaires (with a higher luminous flux than in variant 7) suspended from the ceiling, in one non-continuous light line along the corridor. The use of the non-continuous light line lowered the ceiling and wall illumination uniformity compared to variant 7 while maintaining the mean illuminance value.

Lighting variant 9 (Figure 12) was implemented with the use of 20 E-type luminaires located on the walls, in two rows along the corridor. This variant was characterized by 
relatively high levels of mean ceiling and wall illuminance, and at the same time relatively low uniformities on these planes.

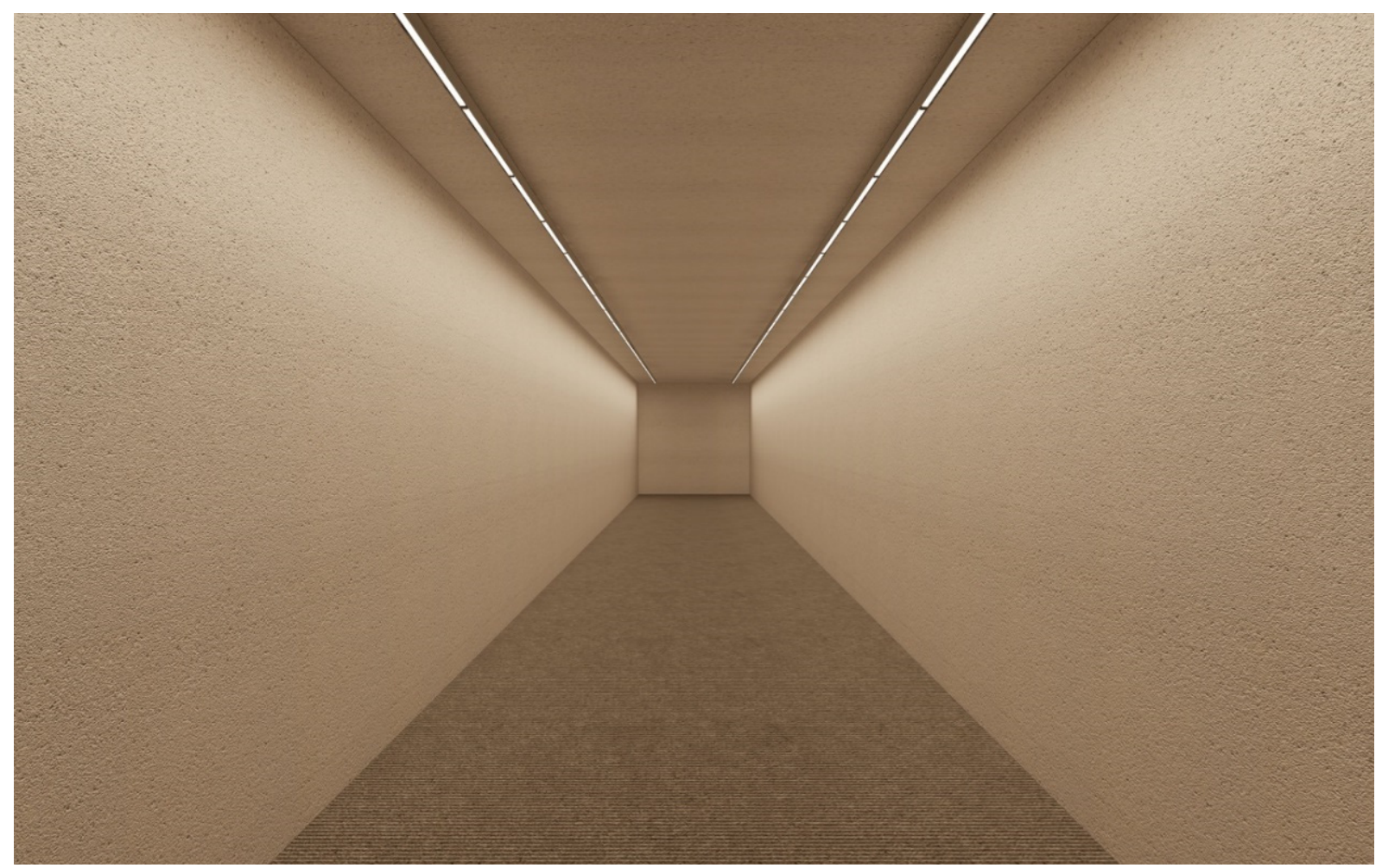

Figure 8. Computer simulation of corridor lighting for variant 5.

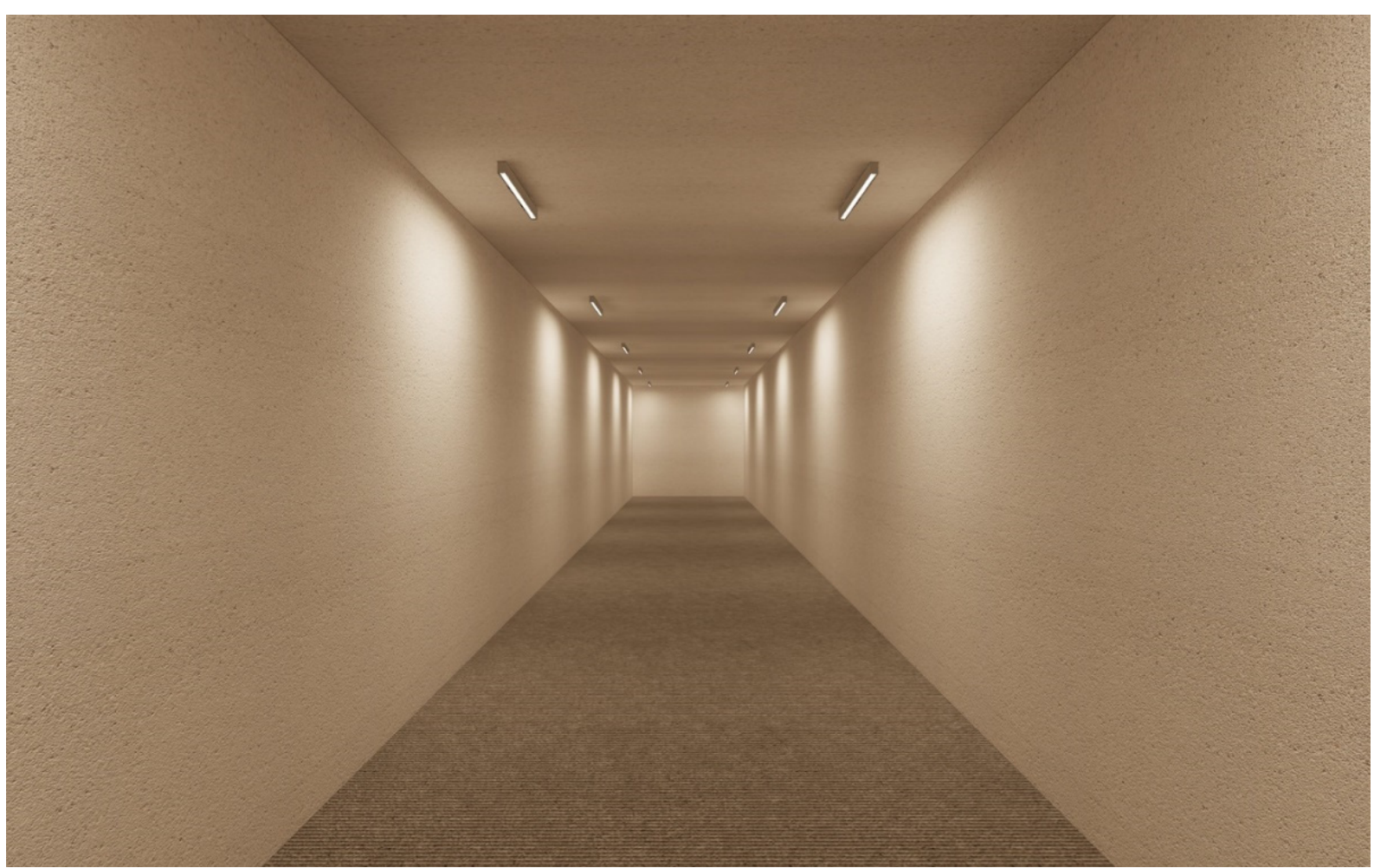

Figure 9. Computer simulation of corridor lighting for variant 6 . 


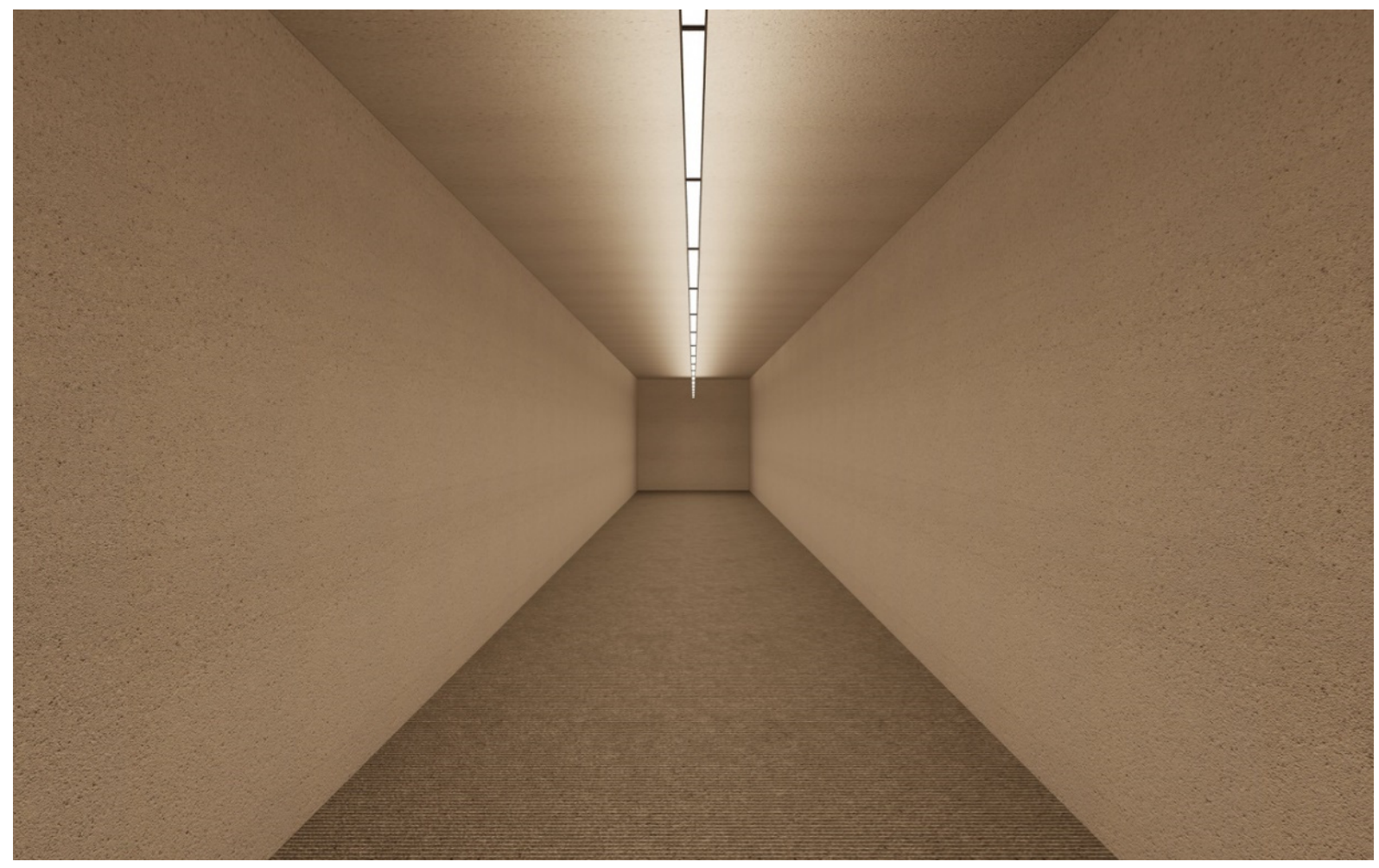

Figure 10. Computer simulation of corridor lighting for variant 7 .

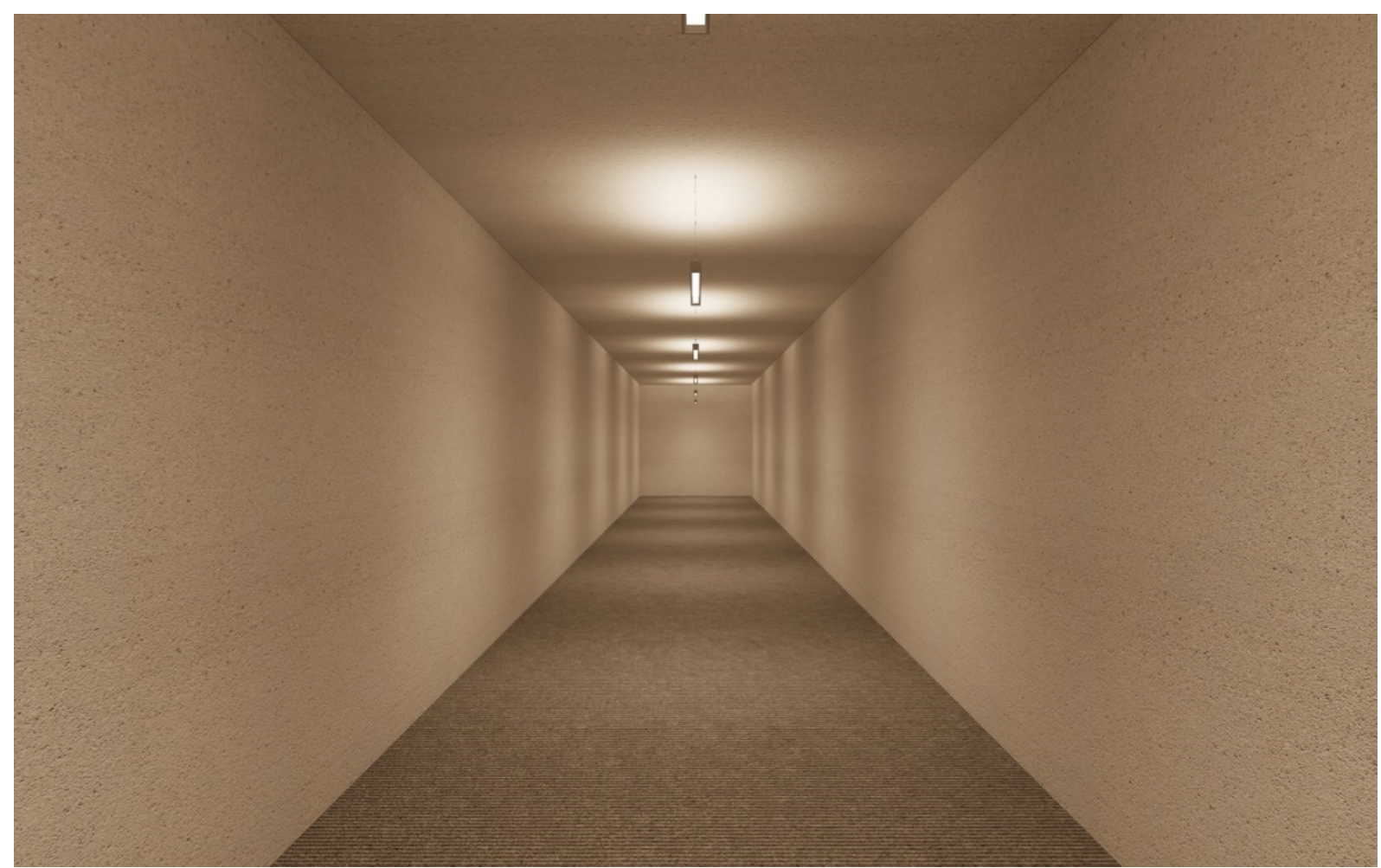

Figure 11. Computer simulation of corridor lighting for variant 8 . 


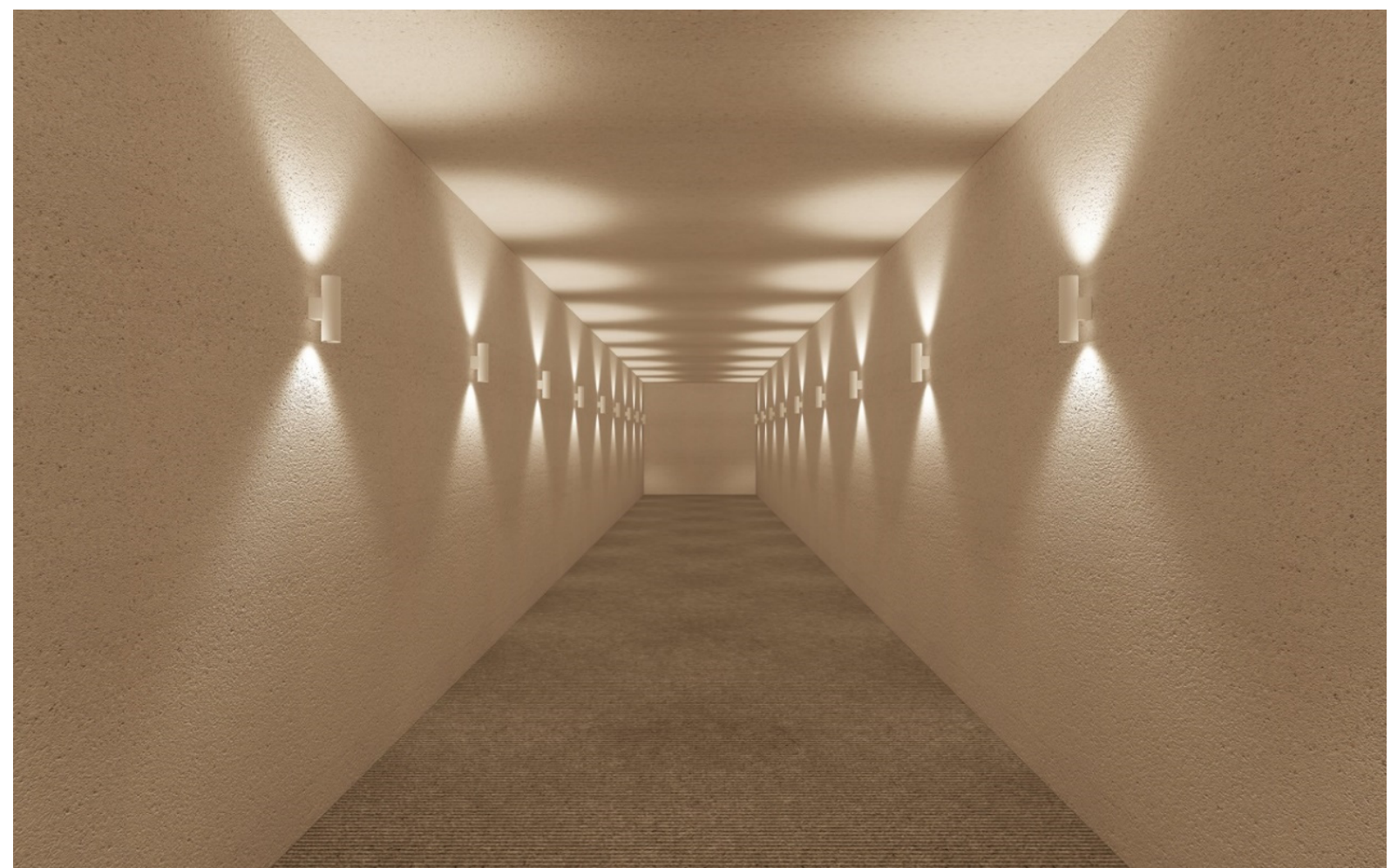

Figure 12. Computer simulation of corridor lighting for variant 9.

Lighting variant 10 (Figure 13) was performed using 40 F-type luminaires located on the walls, in two rows along the corridor.

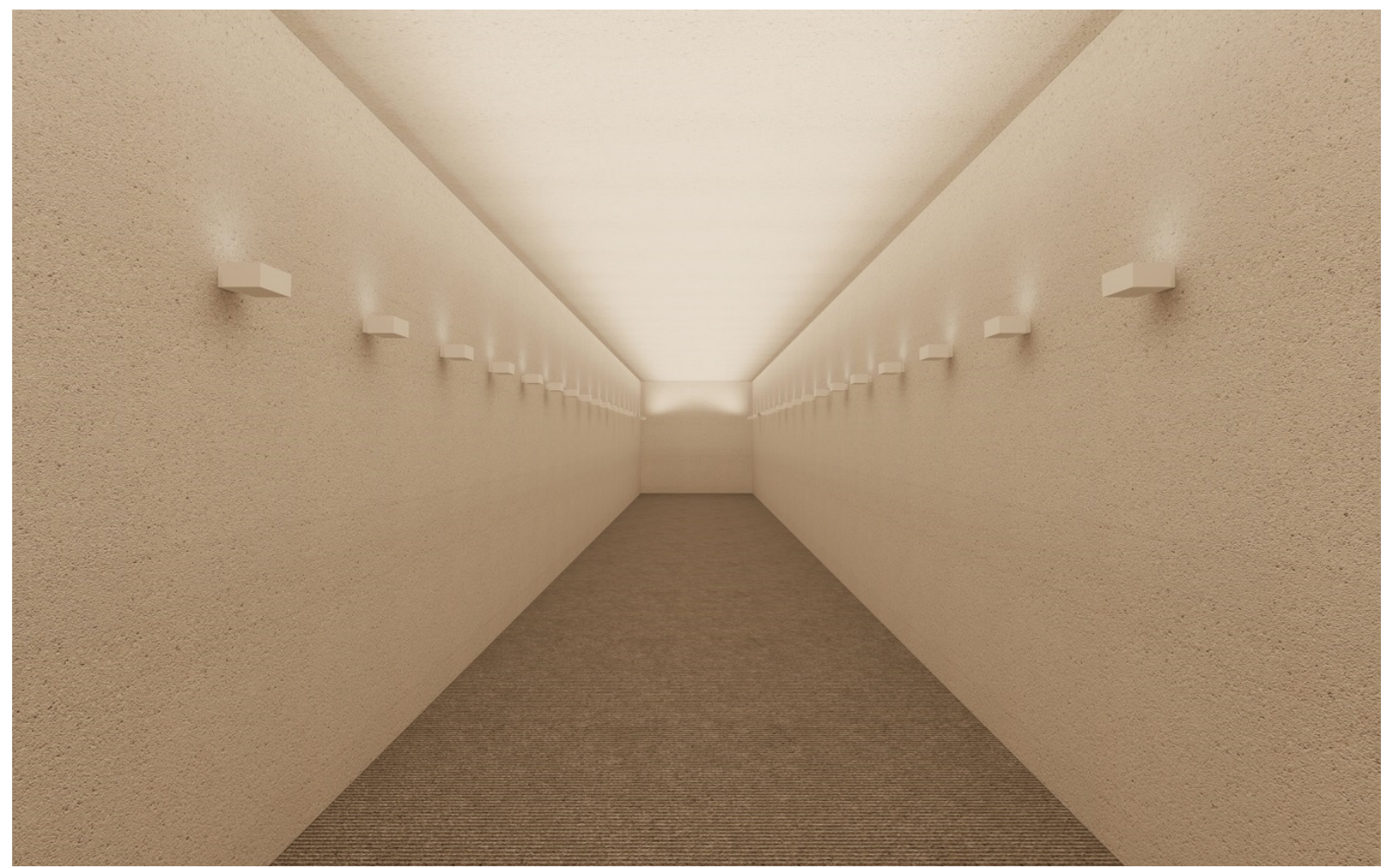

Figure 13. Computer simulation of corridor lighting for variant 10. 
The asymmetric upward light distribution of the luminaires caused a significant increase in average ceiling illuminance with high uniformity. The levels of wall illuminance and uniformity were also high.

The quantitative assessment of the corridor lighting was based on the results of illuminance and luminance calculations from the DIALux software, which are summarized in Table 2.

Table 2. Calculation results of photometric parameters in the corridor.

\begin{tabular}{|c|c|c|c|c|c|c|c|c|c|c|}
\hline \multirow{2}{*}{ Parameter } & \multicolumn{10}{|c|}{ Solution } \\
\hline & 1 & 2 & 3 & 4 & 5 & 6 & 7 & 8 & 9 & 10 \\
\hline $\begin{array}{c}E_{F} \\
{[1 x]}\end{array}$ & \multicolumn{10}{|c|}{100} \\
\hline $\mathrm{L}_{\mathrm{F}}\left[\mathrm{cd} / \mathrm{m}^{2}\right]$ & \multicolumn{10}{|c|}{9.5} \\
\hline $\mathrm{U}_{\mathrm{FMIN}}[-]$ & 0.60 & 0.57 & 0.85 & 0.83 & 0.87 & 0.90 & 0.86 & 0.78 & 0.87 & 0.90 \\
\hline $\begin{array}{l}\mathrm{E}_{\mathrm{W}} \\
{[\mathrm{lx}]} \\
\end{array}$ & 21 & 58 & 51 & 52 & 100 & 97 & 55 & 55 & 76 & 89 \\
\hline $\mathrm{L}_{\mathrm{W}}\left[\mathrm{cd} / \mathrm{m}^{2}\right]$ & 4.6 & 12.9 & 11.4 & 11.5 & 22.4 & 21.6 & 12.2 & 12.2 & 17 & 19.8 \\
\hline $\mathrm{U}_{\text {WMIN }}[-]$ & 0.73 & 0.38 & 0.68 & 0.58 & 0.55 & 0.52 & 0.77 & 0.69 & 0.63 & 0.66 \\
\hline $\begin{array}{c}\mathrm{E}_{\mathrm{C}} \\
{[\mathrm{lx}]}\end{array}$ & 20 & 28 & 32 & 33 & 52 & 53 & 112 & 104 & 94 & 242 \\
\hline $\mathrm{L}_{\mathrm{C}}\left[\mathrm{cd} / \mathrm{m}^{2}\right]$ & 4.4 & 6.2 & 7.0 & 7.3 & 11.5 & 11.7 & 24.9 & 23.1 & 20.9 & 53.9 \\
\hline $\mathrm{U}_{\mathrm{CMIN}}[-]$ & 0.92 & 0.90 & 0.89 & 0.91 & 0.89 & 0.78 & 0.38 & 0.34 & 0.54 & 0.89 \\
\hline $\mathrm{L}_{\mathrm{R}}\left[\mathrm{cd} / \mathrm{m}^{2}\right]$ & 5.8 & 10.4 & 9.9 & 10.0 & 16.5 & 16.1 & 14.7 & 14.3 & 16.1 & 25.1 \\
\hline
\end{tabular}

The use of direct lighting luminaires with a narrow light distribution (type A) made it impossible to obtain the required mean illuminance on the ceiling in variants 1 and 2, and the required mean illuminance on the walls in variant 1 . The application of direct lighting luminaires with a wider light distribution (type B) also limits achieving the recommended illumination on the ceiling and walls in variants 3 and 4 . In these situations, the recommended levels of mean illuminance on the ceiling and walls were not obtained. The use of direct-indirect lighting luminaires with limited light distribution in the lateral direction (type $\mathrm{D}$ ), in variants 7 and 8 , reduces achieving the recommended wall illumination. In these cases, the recommended levels of mean wall illuminance were not obtained. In all cases, the requirements for uniformity on the work plane $(>0.40)$, and on the ceiling and walls $(>0.10)$ were met. The achieved uniformities significantly exceeded the requirements.

Solution 5 was characterized by the lowest installed power density among the variants meeting all lighting requirements whereas the lowest installed power density among the variants meeting all lighting recommendations was characteristic of solution 3 . To sum up, from the point of view of the quantitative lighting assessment made on the basis of illuminance distributions, solutions 5 and 3 should be preferred.

It is worth paying attention to the relationships between the obtained effects (relative average ceiling $\mathrm{E}_{\mathrm{C}} / \mathrm{E}_{\mathrm{F}}$ and wall $\mathrm{E}_{\mathrm{W}} / \mathrm{E}_{\mathrm{F}}$ illuminances) and the efficiency of lighting solutions (utilization factor (UF) and installed power density (PD)). Figure 14 illustrates this relation. 


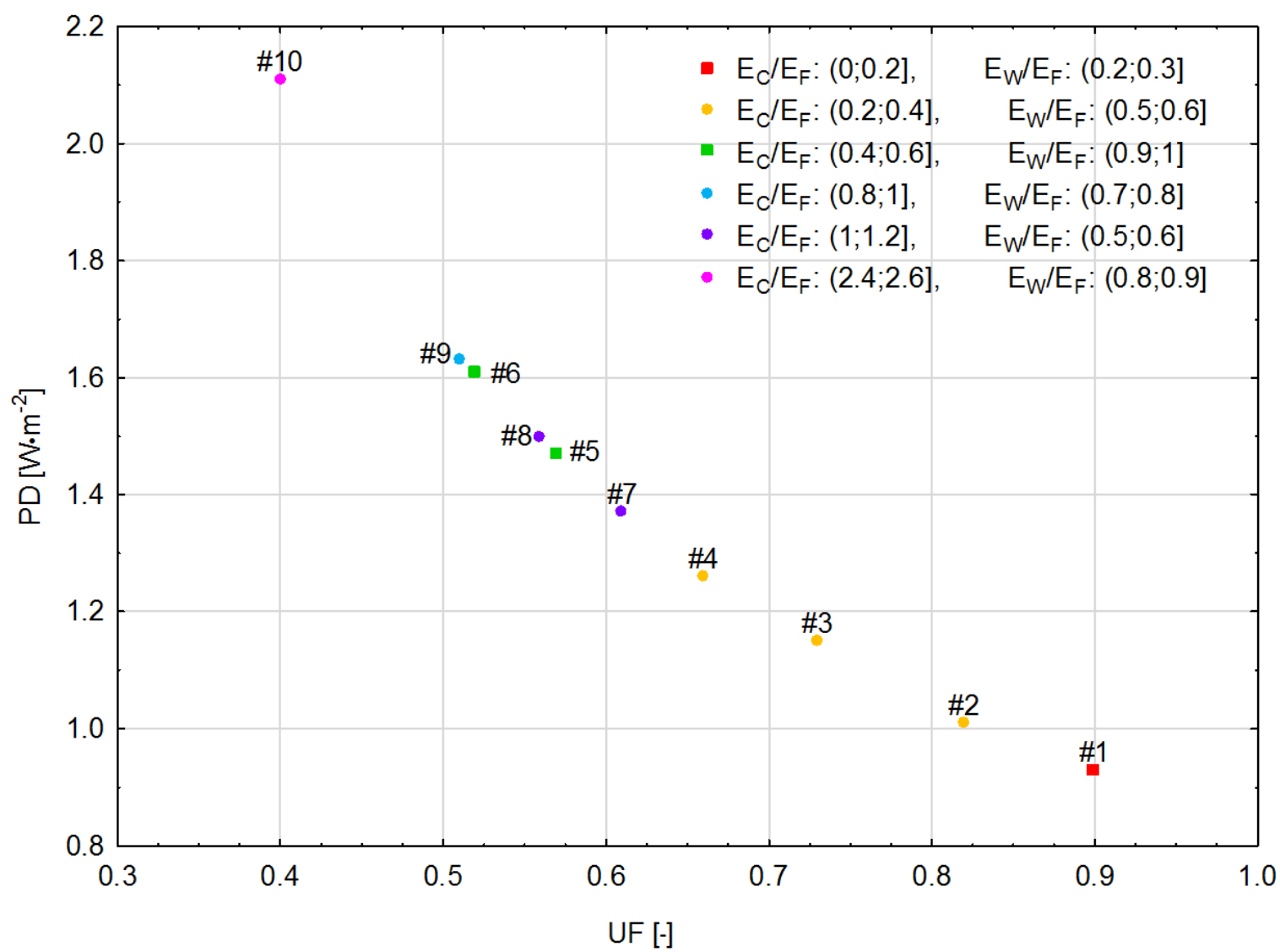

Figure 14. Relationship between power density (PD) and utilization factor (UF), categorized by $E_{C} / E_{F}$ and $E_{W} / E_{F}$, for the analyzed lighting cases in the corridor.

The analyzed cases were ordered from the most efficient (the highest utilization factor and the lowest power density) solution 1 (in the bottom right corner of the graph) to the least efficient (the lowest utilization factor and the highest power density) solution 10 (in the top left corner of the graph).

It should be noted that solutions 3,5, and 7 (where the continuous lines were applied) are more efficient than solutions 4,6 , and 8 (with the same types of luminaires, but with the non-continuous lines and much higher luminous fluxes of the luminaires). It arises from the luminaire layout, which resulted in a higher utilization factor of solutions 3, 5, and 7.

It is also worth noting that solution 7 is more efficient than solution 5 , and solution 8 is more efficient than solution 6 . It arises from more efficient use of the luminous flux of the luminaires to illuminate the work plane (floor). In solutions 7 and 8, a higher amount of the luminous flux of the luminaires is emitted directly towards the floor than in solutions 5 and 6.

The wall mounted solutions are the least efficient, especially solution 10 where the work plane illumination results only from the luminous flux reflected from the ceiling and walls.

\subsection{The Survey and Qualitative Assessment of Lighting}

In the second stage of the research, the survey in two groups were conducted: For the first group B in the box and for the second group C in the computer room. Table 3 presents the results of measurements of the mean luminance of the corridor image presented to the respondents from group $\mathrm{B}$ on the computer screen located in the box. 
Table 3. The measured values of the mean luminance $\left[\mathrm{cd} \cdot \mathrm{m}^{-2}\right]$ of the corridor image presented on the computer screen in the box for group B.

\begin{tabular}{ccccccccccc}
\hline \multirow{2}{*}{ Parameter } & \multicolumn{10}{c}{ Solution } \\
\cline { 2 - 11 } & $\mathbf{1}$ & $\mathbf{2}$ & $\mathbf{3}$ & $\mathbf{4}$ & $\mathbf{5}$ & $\mathbf{6}$ & $\mathbf{7}$ & $\mathbf{8}$ & $\mathbf{9}$ & $\mathbf{1 0}$ \\
\hline $\mathrm{L}_{\mathrm{FM}}\left[\mathrm{cd} / \mathrm{m}^{2}\right]$ & 15.07 & 12.86 & 13.58 & 13.47 & 13.49 & 13.65 & 13.98 & 14.01 & 13.37 & 15.29 \\
\hline $\mathrm{L}_{\mathrm{WM}}\left[\mathrm{cd} / \mathrm{m}^{2}\right]$ & 4.06 & 11.00 & 18.96 & 20.01 & 41.07 & 33.63 & 21.72 & 23.84 & 29.59 & 42.86 \\
\hline $\mathrm{L}_{\mathrm{CM}}\left[\mathrm{cd} / \mathrm{m}^{2}\right]$ & 4.37 & 7.90 & 10.20 & 10.39 & 22.16 & 21.98 & 41.45 & 29.20 & 44.22 & 87.97 \\
\hline $\mathrm{L}_{\mathrm{RM}}\left[\mathrm{cd} / \mathrm{m}^{2}\right]$ & 5.89 & 10.87 & 16.68 & 17.65 & 33.43 & 28.99 & 23.24 & 23.15 & 29.35 & 45.19 \\
\hline
\end{tabular}

The following parameters were given for each lighting situation:

- $\mathrm{L}_{\mathrm{FM}}$ - the mean luminance of part of the floor in the corridor displayed on the screen.

- $\mathrm{L}_{\mathrm{WM}}$ - the mean luminance of part of the walls in the corridor displayed on the screen.

- $\mathrm{L}_{\mathrm{CM}}$ - the mean luminance of part of the ceiling in the corridor displayed on the screen.

- $\mathrm{L}_{\mathrm{RM}}$ - the mean luminance of part of the entire corridor displayed on the screen.

The mean luminance level on the wall behind the screen (in the field of view of the respondents from group B) was about $10 \mathrm{~cd} \cdot \mathrm{m}^{-2}$. The luminance distribution in the computer room and on the computer screens in group $\mathrm{C}$ was not controlled.

On the basis of all completed questionnaires, for the brightness and uniformity for the individual lit planes and corridor, the mean values (Mean), medians (Median), minimum (Min.), maximum (Max.), and standard deviations (SD) of the mean values were calculated for each group and each lighting situation. The symbols used indicate: Lighting situation (from 1 to 10), analyzed feature (B-brightness, U-uniformity), illuminated planes (F-floor, $\mathrm{W}$-walls, $\mathrm{C}$-ceiling, $\mathrm{R}$ - the entire corridor), and group ((B)—group $\mathrm{B}$, (C)-group C).

\subsection{Brightness and Uniformity Perception of Consecutive Computer Images of Corridor}

On the basis of the obtained results, the changes in the brightness and uniformity perception on a given plane and the corridor in the consecutive situations were analyzed for each group.

Figures 15-18 show the floor brightness and uniformity perception for groups B and C.

In every group, it was estimated that the highest mean floor brightness occurred in variant $1\left(\mathrm{~B}_{\mathrm{F}(\mathrm{B})}=5.4, \mathrm{~B}_{\mathrm{F}(\mathrm{C})}=5.7\right)$. The perception of a higher floor brightness in variant 1 was associated with a much lower ceiling and wall brightness than in the other variants. For the remaining variants, the average floor brightness perception in group $\mathrm{B}$ ranged between 3.8 and 4.3, and in group $C$ it ranged between 4.4 and 5.1. The floor brightness for variants 2 to 10 was therefore assessed very similarly in each group. However, for each situation, group $\mathrm{C}$ estimated that the floor brightness levels were higher compared to the ones evaluated by group B.

In every group, it was assessed that the lowest mean floor uniformity occurred in variant $1\left(\mathrm{U}_{\mathrm{F}(\mathrm{B})}=1.6, \mathrm{U}_{\mathrm{F}(\mathrm{C})}=2.0\right)$, and then in variant 2 . In each group it was estimated that in variants 3,5 and 7 (continuous light lines) the floor illumination uniformity was higher than in variants 4, 6 and 8 (non-continuous light lines). The floor illumination uniformity in variant 10 was also rated very high.

Figures 19-22 show the wall brightness and uniformity perception for groups B and C. 


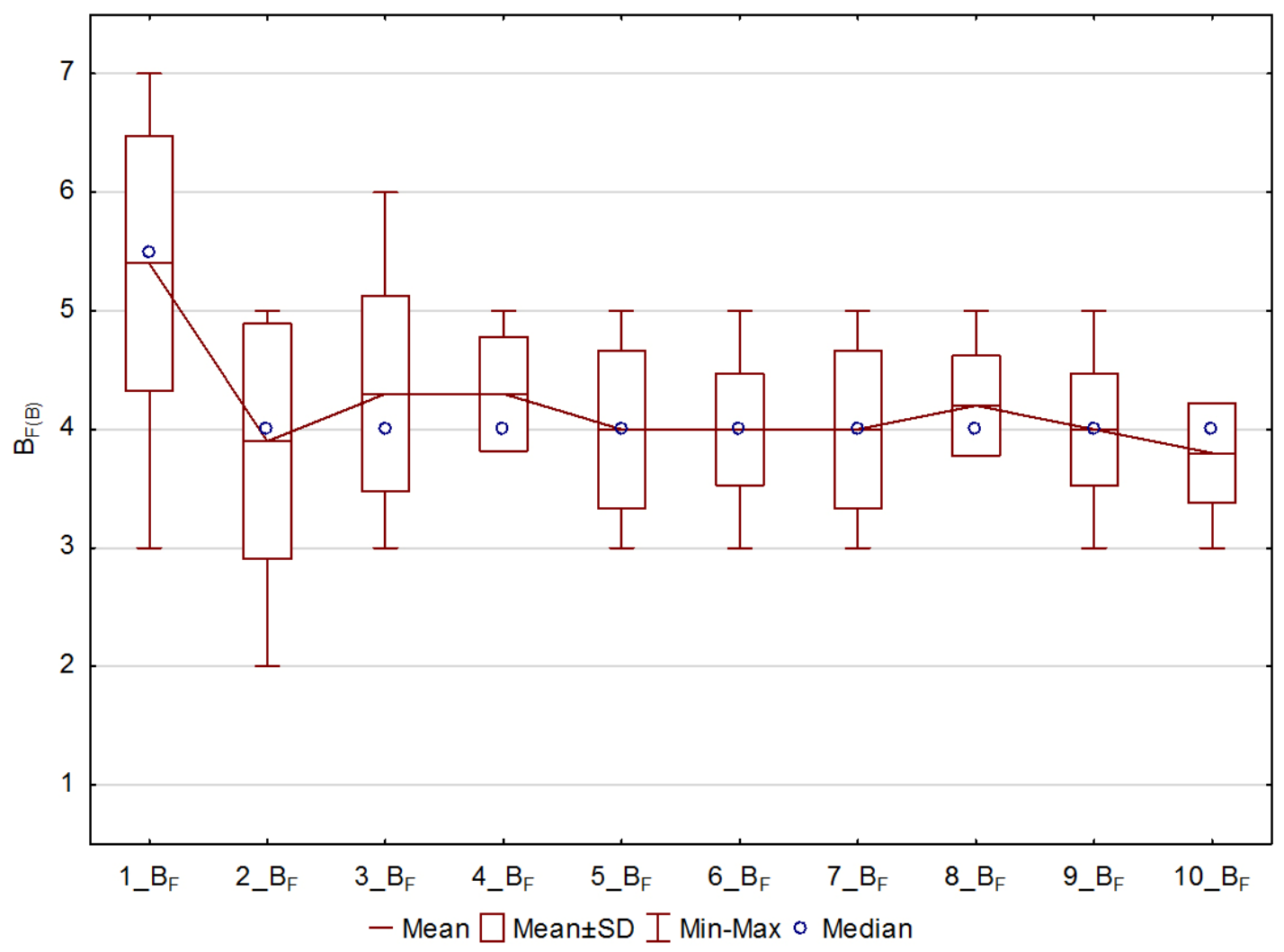

Figure 15. Floor brightness perception for group B.

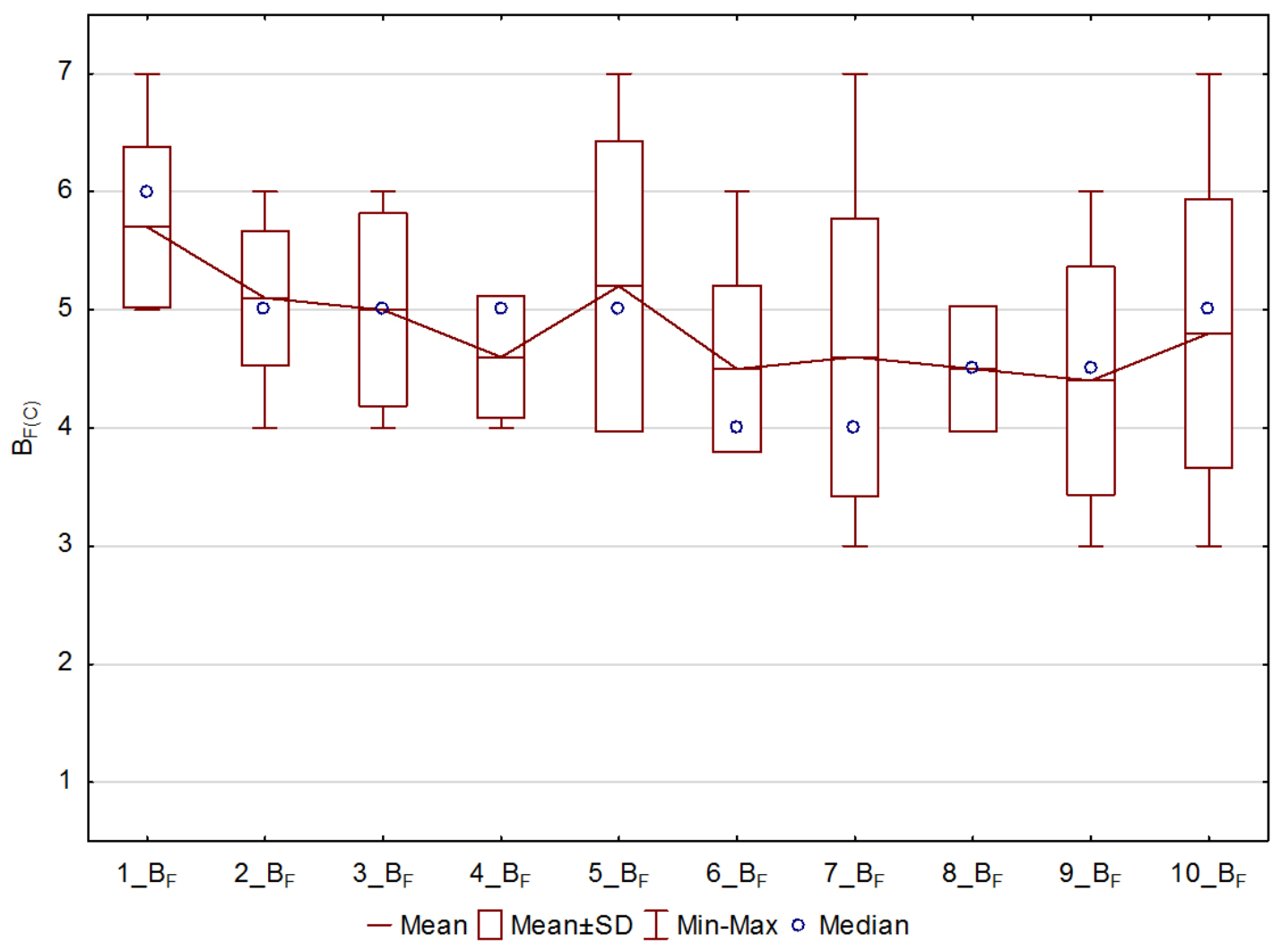

Figure 16. Floor brightness perception for group C. 


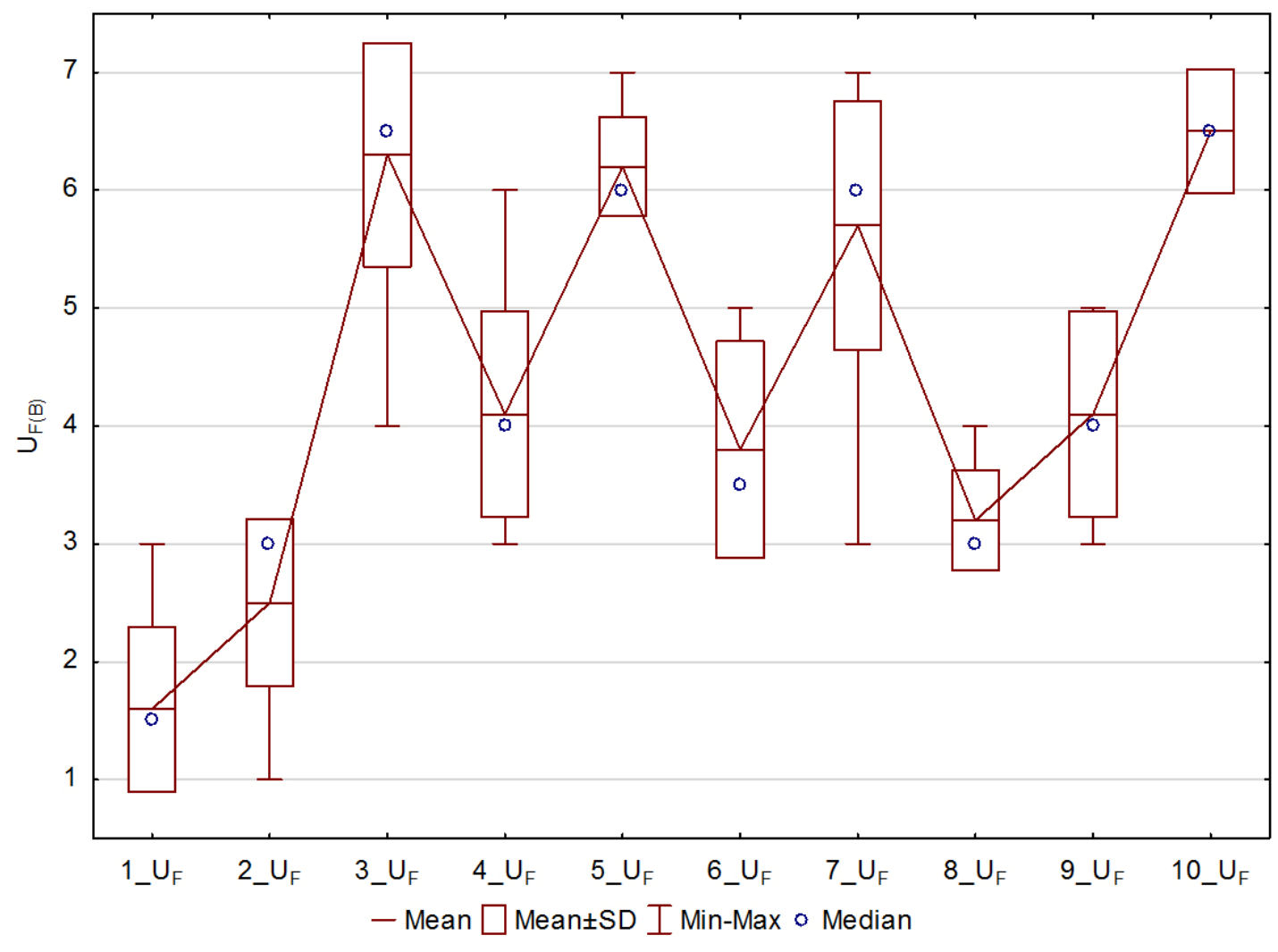

Figure 17. Floor uniformity perception for group B.

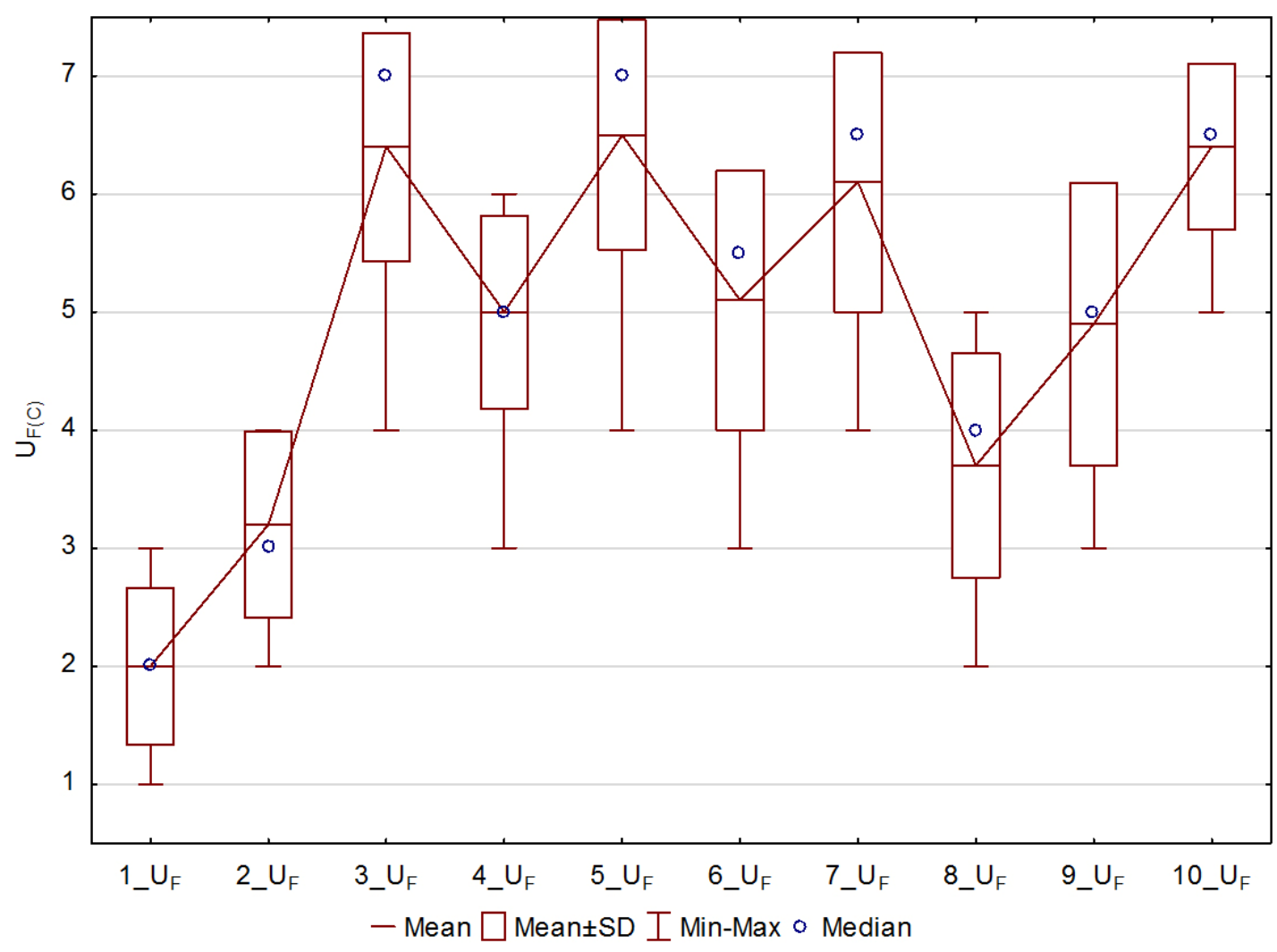

Figure 18. Floor uniformity perception for group C. 


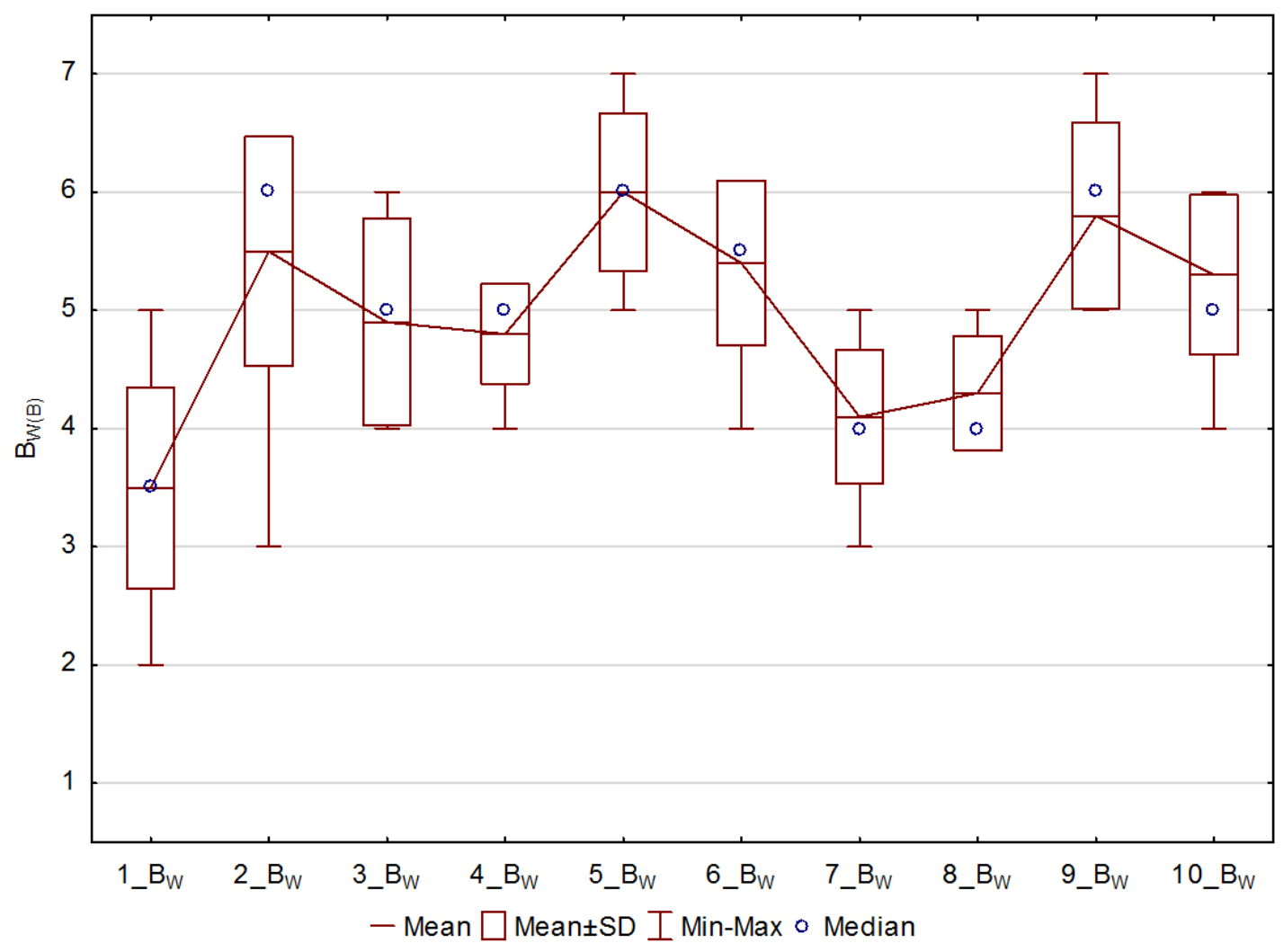

Figure 19. Wall brightness perception for group B.

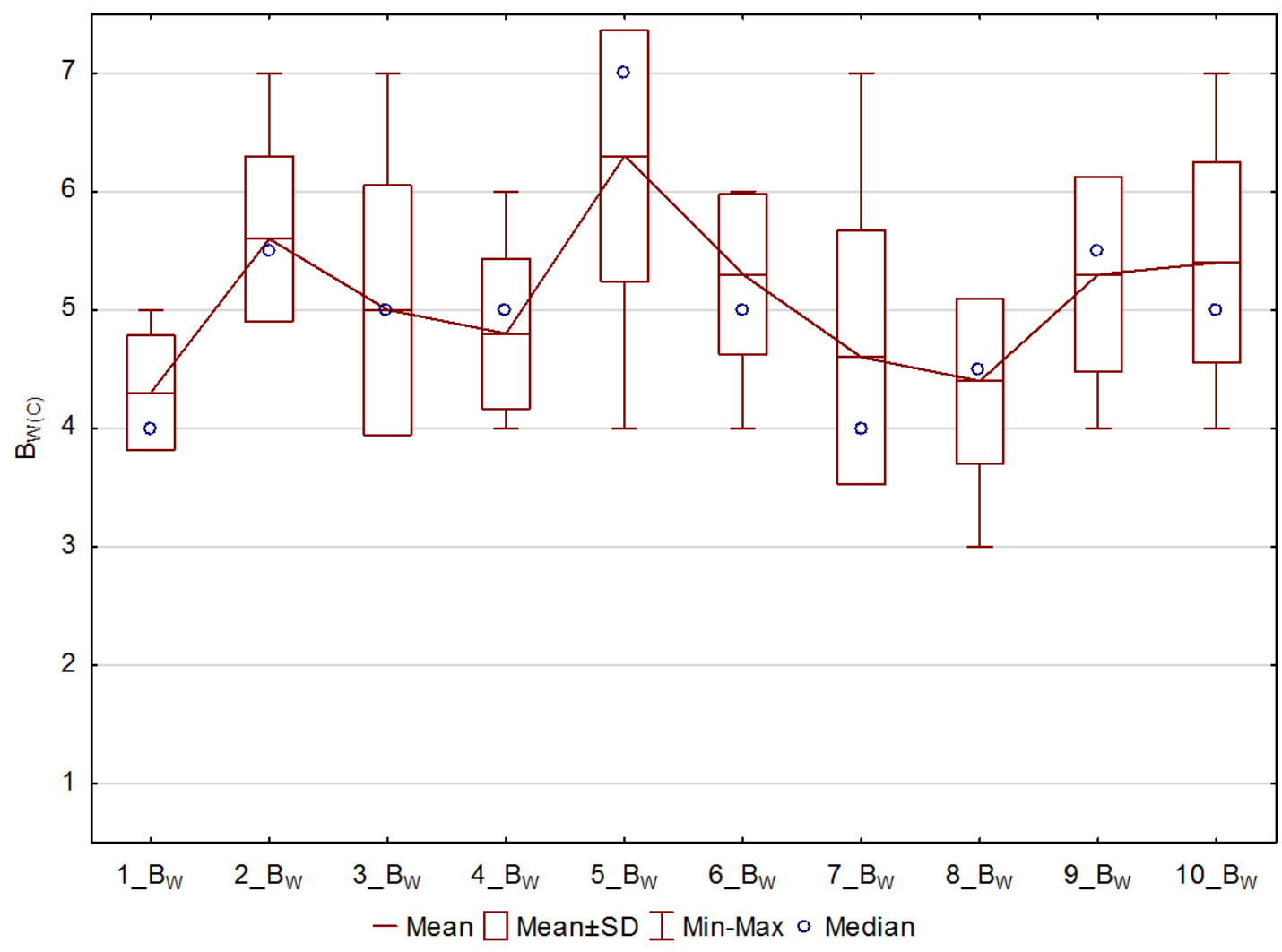

Figure 20. Wall brightness perception for group C. 


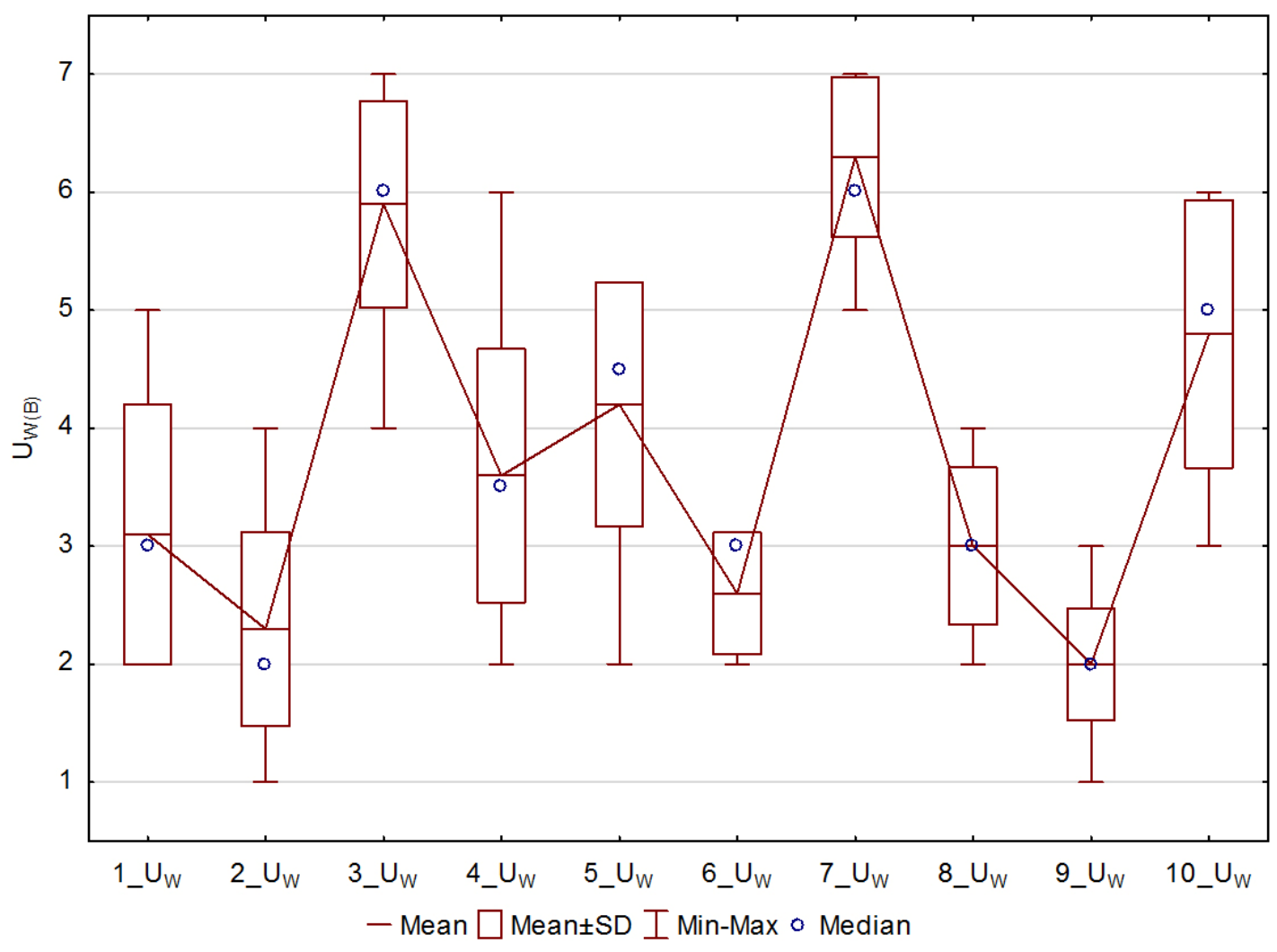

Figure 21. Wall uniformity perception for group B.

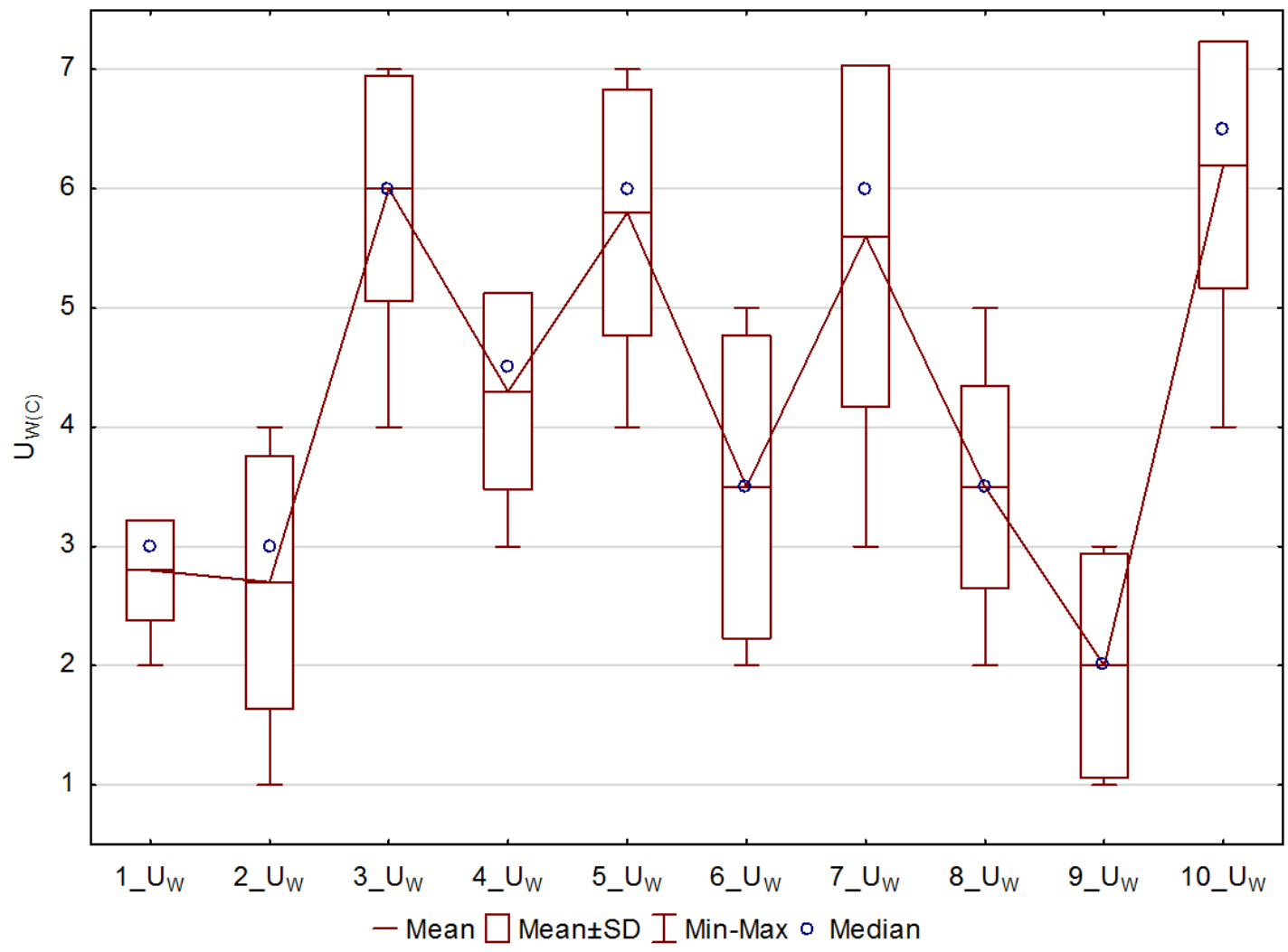

Figure 22. Wall uniformity perception for group C. 
When analyzing the results, it can be concluded that in each group, it was assessed that the lowest mean wall brightness occurred in variant $1\left(\mathrm{~B}_{\mathrm{W}(\mathrm{B})}=3.5, \mathrm{~B}_{\mathrm{W}(\mathrm{C})}=4.3\right)$ whereas the highest mean wall brightness occurred in variant $5\left(\mathrm{~B}_{\mathrm{W}(\mathrm{B})}=6.0, \mathrm{~B}_{\mathrm{W}(\mathrm{C})}=6.3\right)$. In each group, almost identical nature of changes in the wall brightness assessment for consecutive variants can also be observed. It was assessed that in variants 7 and 8 , despite the high mean luminance, the wall brightness was low (only higher than the brightness in variant 1 ). It was estimated that in variant 3 the wall brightness perception was lower than in option 2 , despite a higher mean luminance in option 3 . This could be connected with the sequence of presented variants to the respondents.

In each group, the respondents estimated that the lowest mean wall uniformity occurred in variant $9\left(\mathrm{U}_{\mathrm{W}(\mathrm{B})}=2.0, \mathrm{U}_{\mathrm{W}(\mathrm{C})}=2.0\right)$, and then in variant 2 . The perceived wall brightness contrasts were definitely the highest in these variants. In each group, the low wall uniformity was also observed in variants 1,6 , and 8 . Like in the case of the floor, also, when assessing the wall uniformity, the high uniformity was noticed in variants 3, 5, 7 and 10. In group $B$, the wall uniformity in variants 5 and 10 were rated slightly lower. and $\mathrm{C}$.

Figures $23-26$ show the ceiling brightness and uniformity perception for groups B

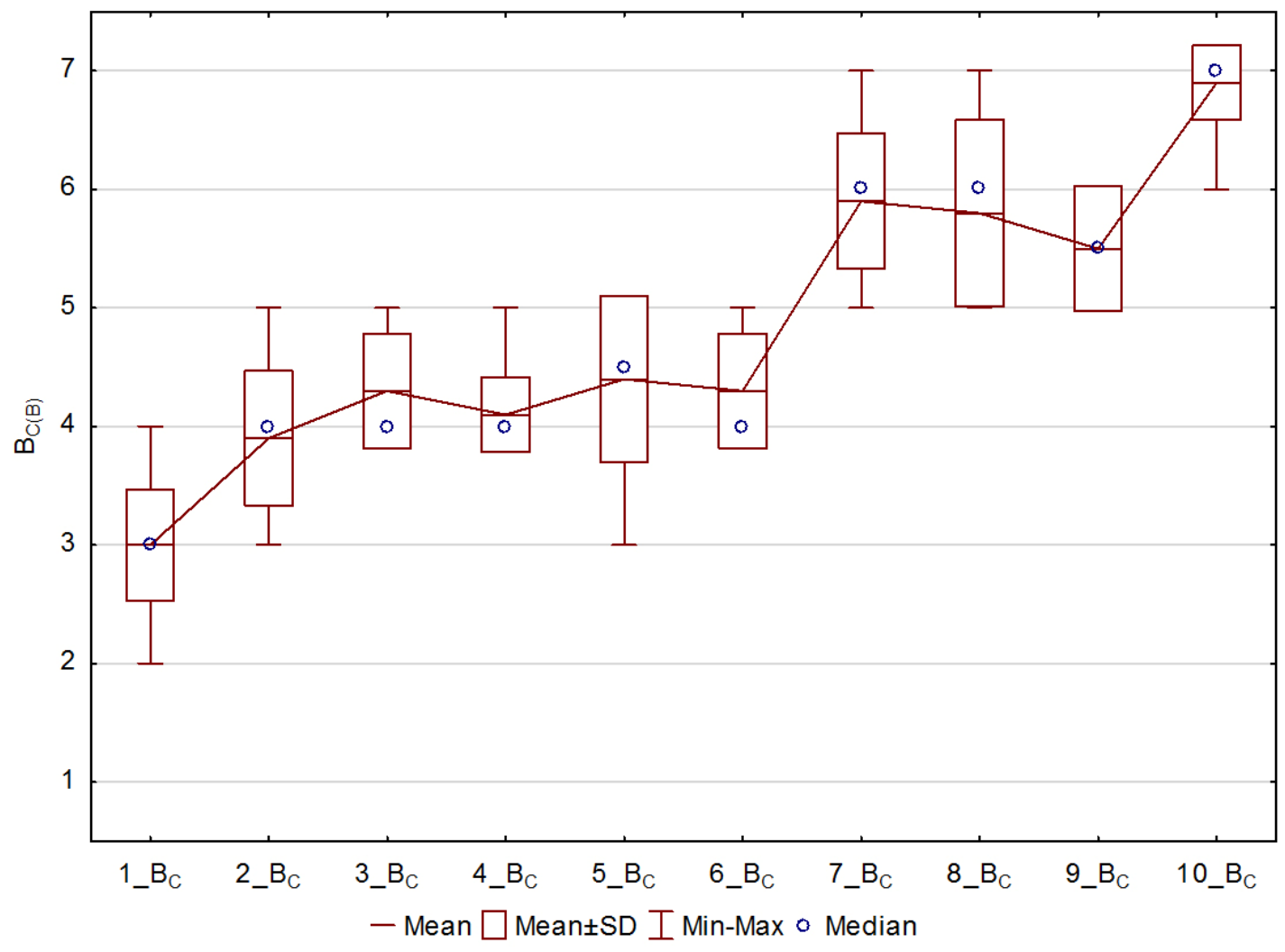

Figure 23. Ceiling brightness perception for group B. 


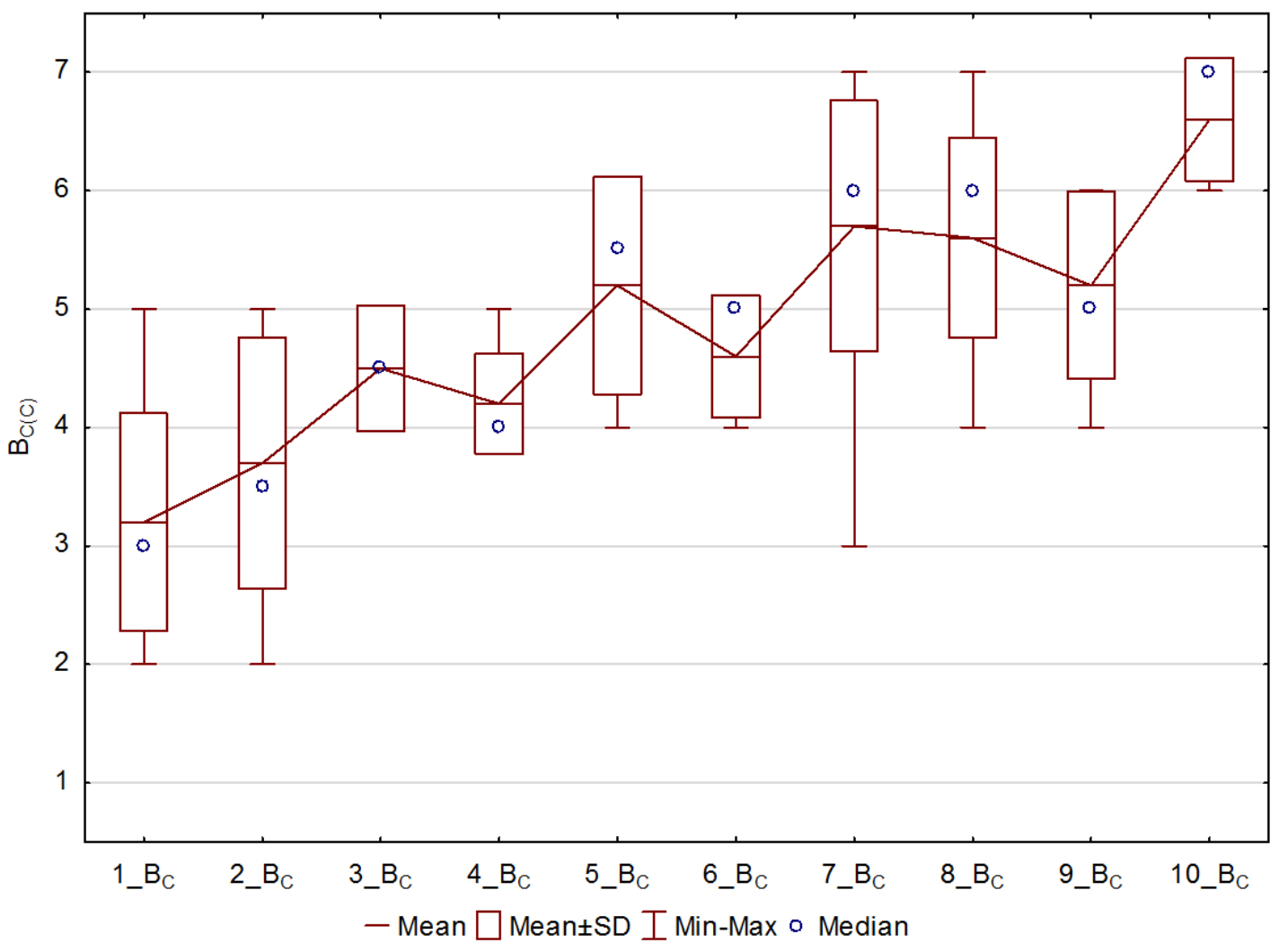

Figure 24. Ceiling brightness perception for group C.

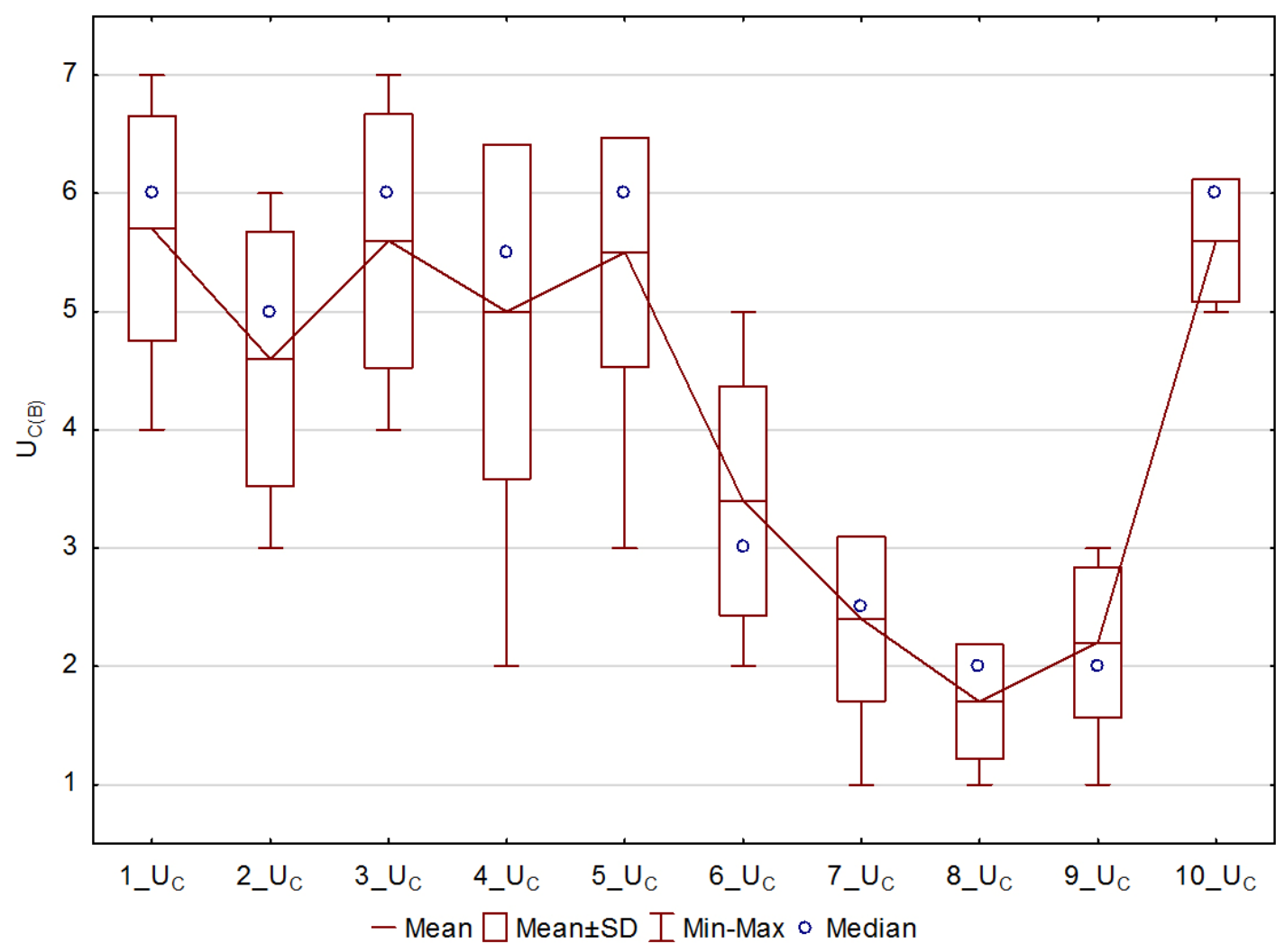

Figure 25. Ceiling uniformity perception for group B. 


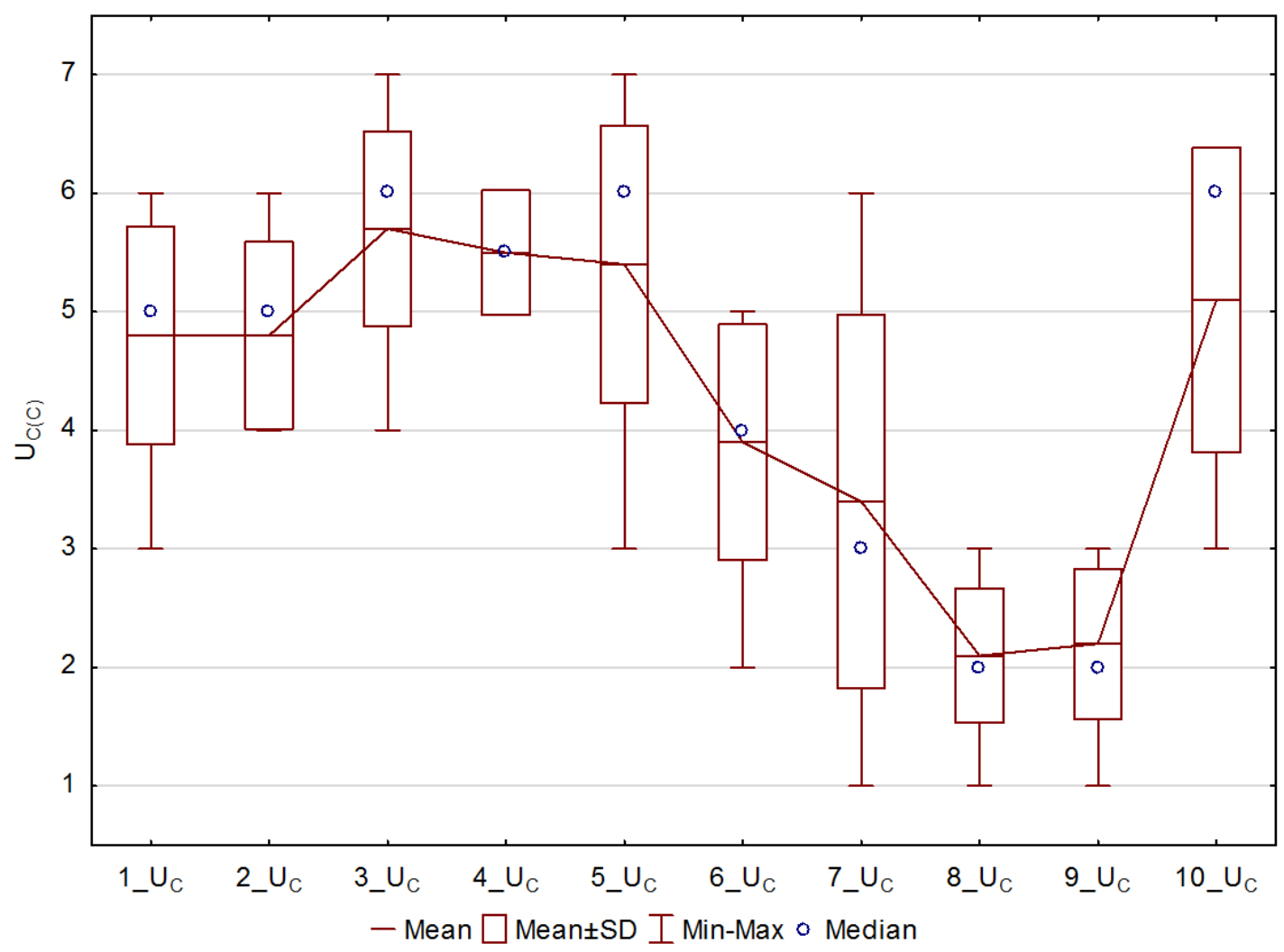

Figure 26. Ceiling uniformity perception for group C.

In each group, it was estimated that the lowest mean ceiling brightness occurred in variant $1\left(\mathrm{~B}_{\mathrm{C}(\mathrm{B})}=3.0, \mathrm{~B}_{\mathrm{C}(\mathrm{C})}=3.2\right)$, and then in variant 2 . Very similar assessments were recorded for variants $3,4,5$, and 6 , and then higher for variants 7,8 and 9 . The ceiling brightness was rated the highest in variant $10\left(B_{C(B)}=6.9, B_{C(C)}=6.6\right)$. It should be noted that in variant 5 group $C$ assessed the ceiling brightness significantly higher than group B. In each group, the identical nature of changes in the ceiling brightness assessment for consecutive variants can be observed. It was estimated that in variant 9 the ceiling brightness perception was lower than in variant 8 , despite a higher mean luminance in variant 9 . This could be connected with a significantly higher wall brightness perception in variant 9 compared to variant 8 .

In each group, the ceiling uniformity was rated very low in variants $8,9,7$, and 6 , too. In none of these cases was the mean ceiling uniformity value higher than 4.00 , and in the variant where the uniformity was rated the lowest (situation 8 ), the mean values for the groups were: $U_{C(B)}=1.7, U_{C(C)}=2.1$. As for the direct lighting situations 1-5 (the exception was variant 6-asymmetric lighting with the non-continuous lines) and for the indirect lighting-variant 10, the ceiling uniformity was rated relatively high.

Figures 27-30 show the entire corridor brightness and uniformity perception for groups $\mathrm{B}$ and $\mathrm{C}$. 


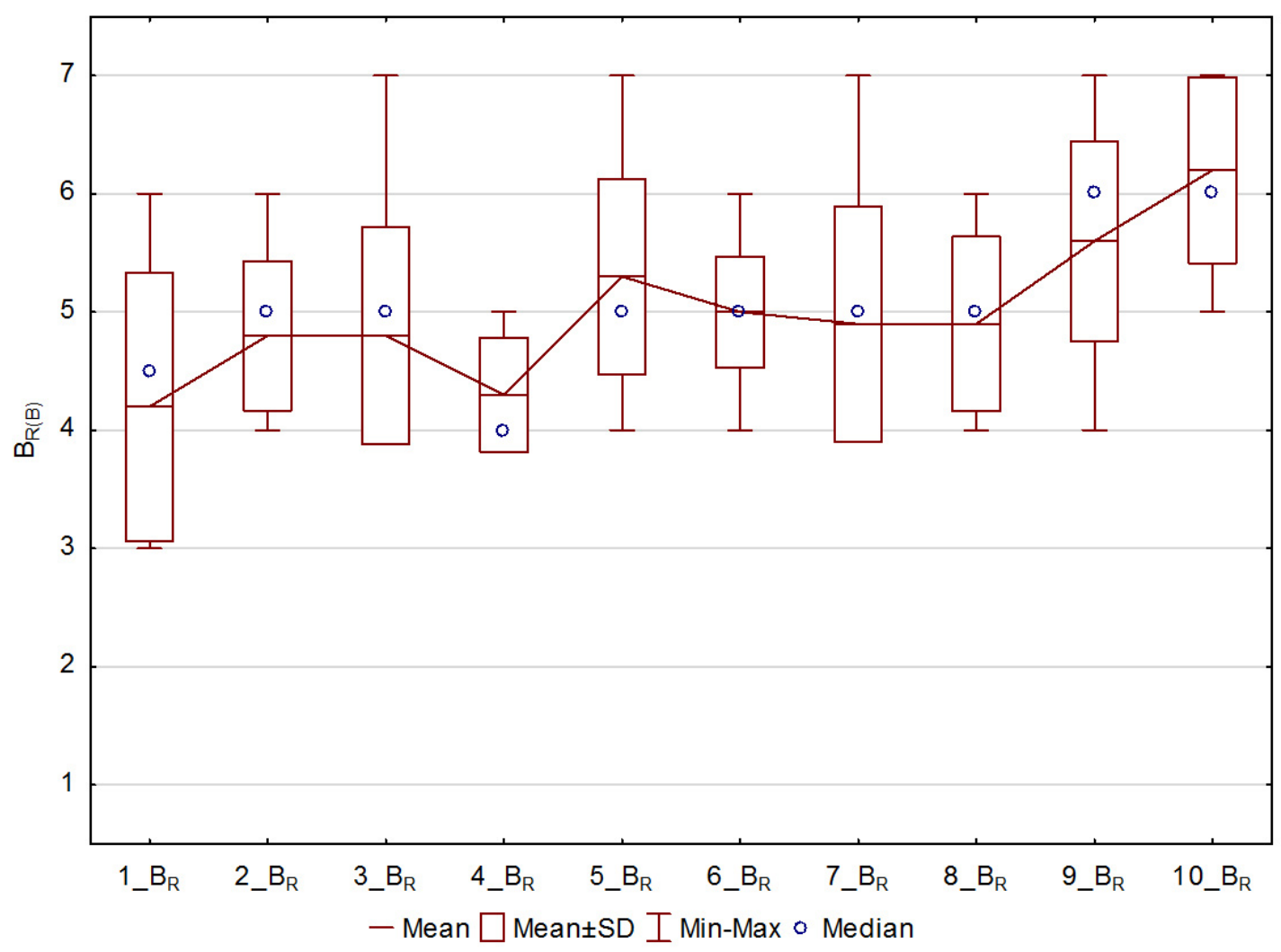

Figure 27. Corridor brightness perception for group B.

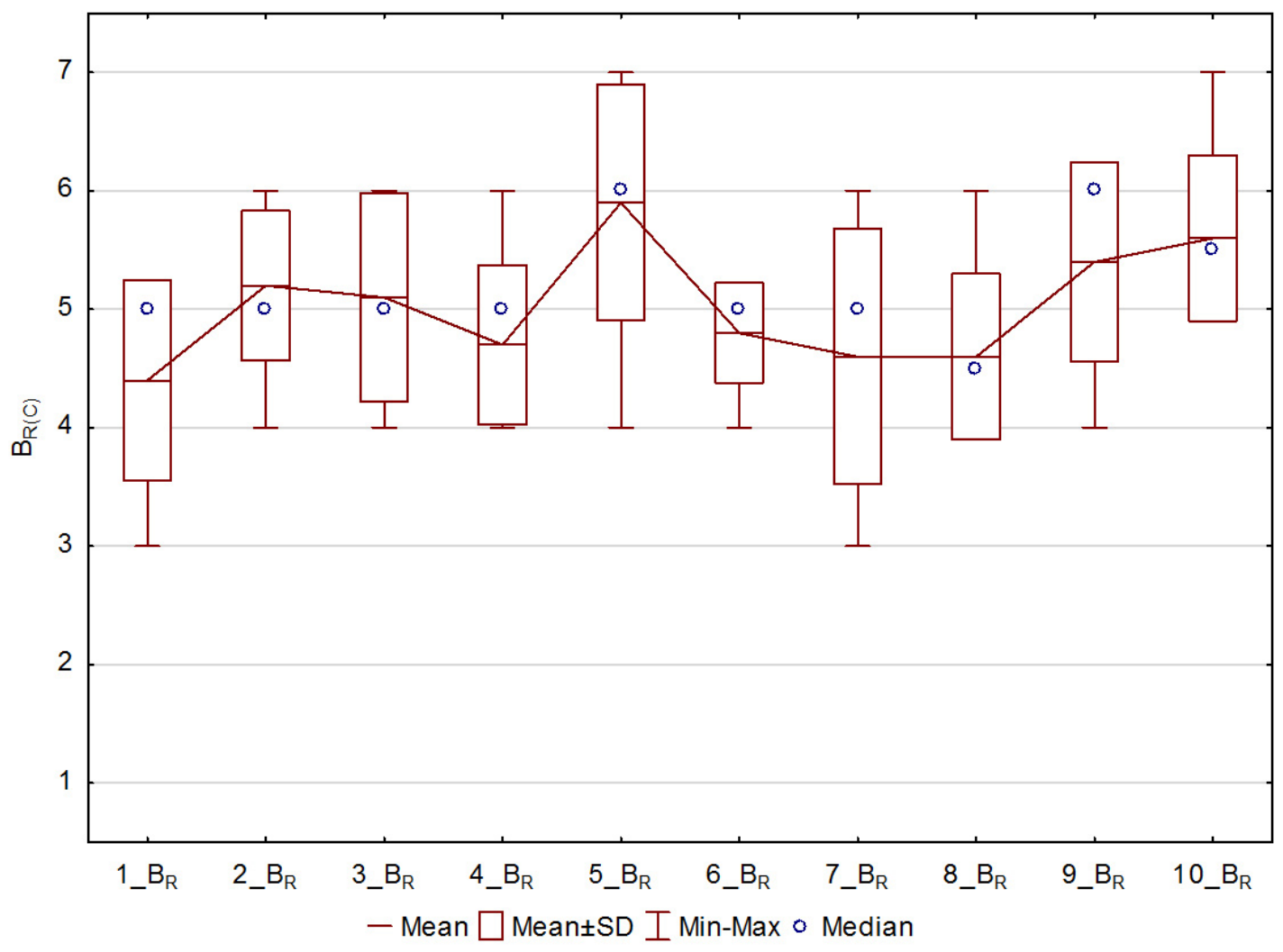

Figure 28. Corridor brightness perception for group C. 


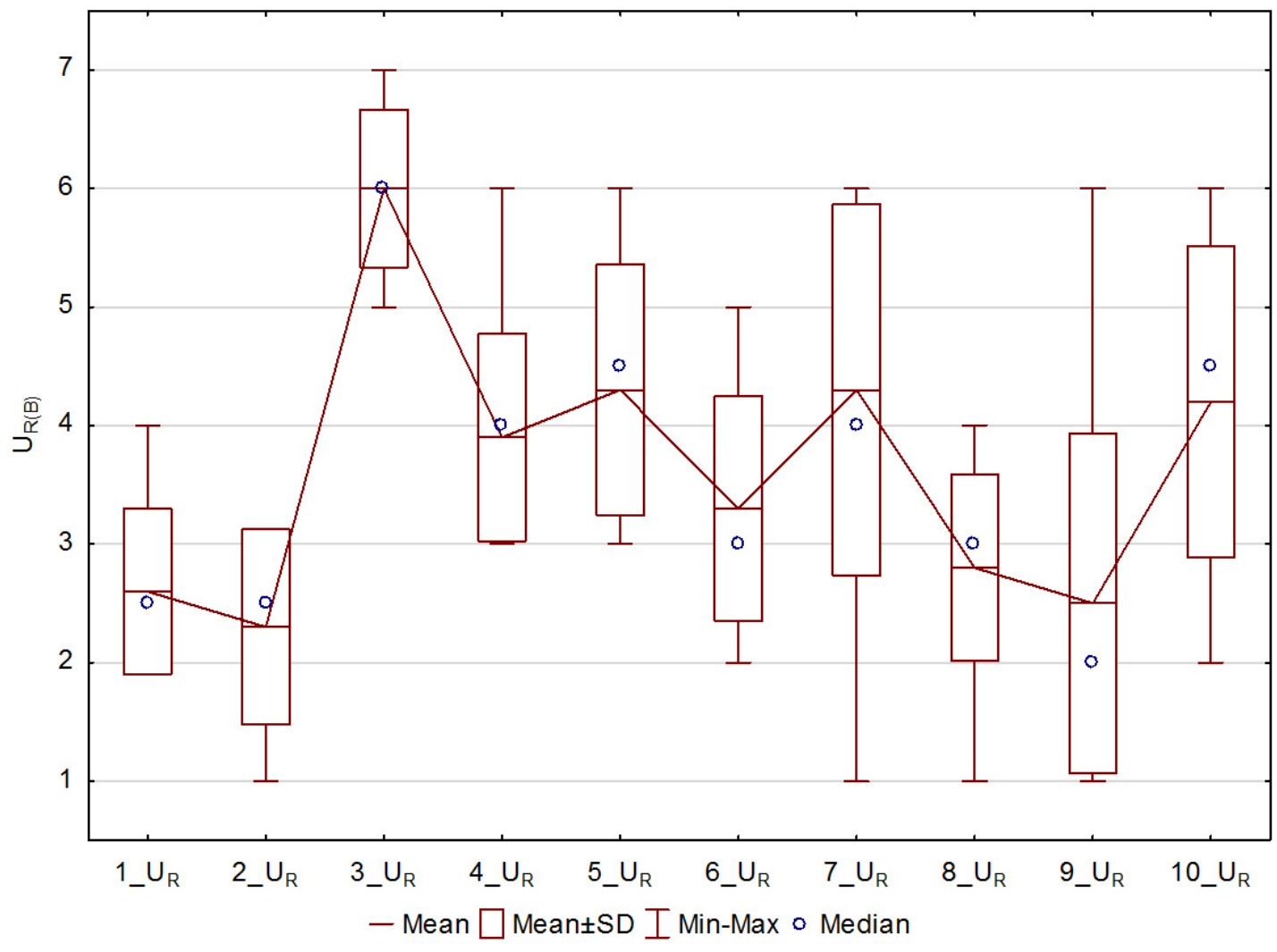

Figure 29. Corridor uniformity perception for group B.

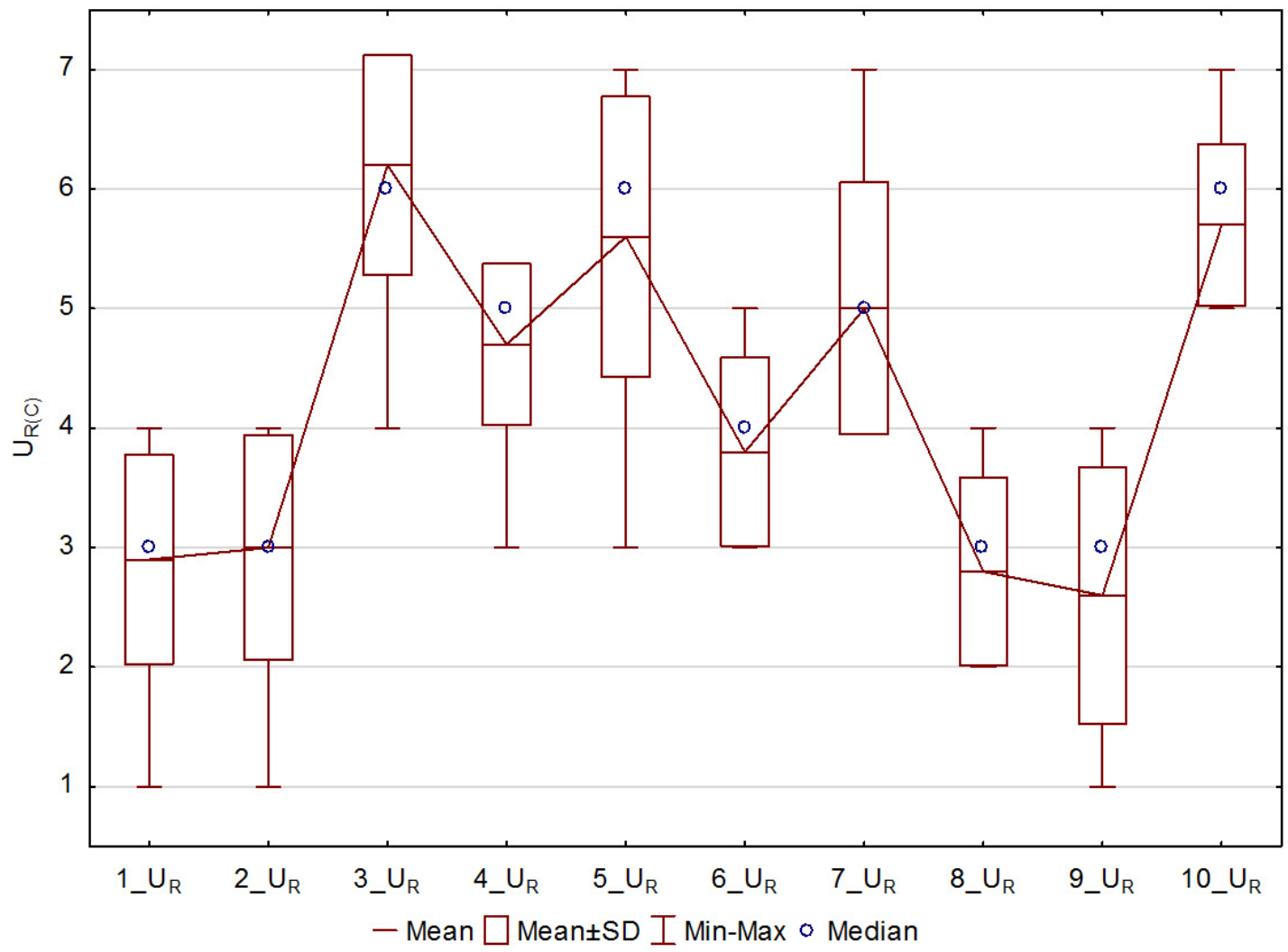

Figure 30. Corridor uniformity perception for group C. 
In each group, the respondents estimated that the lowest mean corridor brightness occurred in variant $1\left(\mathrm{~B}_{\mathrm{R}(\mathrm{B})}=4.2, \mathrm{~B}_{\mathrm{R}(\mathrm{C})}=4.4\right)$. It was also assessed that the highest mean corridor brightness occurred in variant 10 for group $B\left(B_{R(B)}=6.2\right)$ and in variant 5 for group $C\left(B_{R(C)}=5.9\right)$. The high mean corridor brightness was also observed in variant 9. The relatively high assessment of the corridor brightness in variant 2 and relatively low assessment of the corridor brightness in variant 6 should be noted, too. This can be connected to the mean brightness of the variants directly presented earlier-low in variant 1 and high in variant 5 . In each group, a similar nature of the changes in the corridor brightness assessment can be observed for the consecutive variants.

In each group, it was estimated that the mean corridor uniformity was very low in situations $1,2,8$, and 9 . In none of these situations the mean corridor uniformity was higher than 3.00. The lowest assessments were assigned to the corridor uniformity, for group $B$ in variant $2\left(U_{R(B)}=2.3\right)$, and for group $C$ in variant $9\left(U_{R(C)}=2.6\right)$. In each group, it was estimated that the corridor uniformity was higher in variant 3 than 4 , in variant 5 than 6 and in variant 7 than 8 (continuous light lines versus non-continuous light lines). In each group, the corridor uniformity was rated the highest in variant $3: \mathrm{U}_{\mathrm{R}(\mathrm{B})}=6.0, \mathrm{U}_{\mathrm{R}(\mathrm{C})}=6.2$.

Finally, using the non-parametric Wald-Wolfowitz test, it was assessed in Statistica ver. 13.3 for how many and which cases the difference between the brightness and uniformity perception of the individual planes and the corridor between the groups was statistically significant. Table 4 presents the mean and SD values for brightness and uniformity perception, and the tests results.

Table 4. The Wald-Wolfowitz runs test results (Valid $\mathrm{N}_{(C)}=10$, Valid $\mathrm{N}_{(B)}=10$ ).

\begin{tabular}{|c|c|c|c|c|c|c|c|c|c|c|}
\hline Variable & $\operatorname{Mean}_{(C)}$ & $\mathrm{SD}_{(\mathrm{C})}$ & $\operatorname{Mean}_{(B)}$ & $\mathrm{SD}_{(\mathrm{B})}$ & $\mathrm{Z}$ & $p$-Value & Z Adjstd & $p$-Value & No. of Runs & No. of Ties \\
\hline $1 \_B_{C}$ & 3.2 & 0.9189 & 3.0 & 0.4714 & 0.9189 & 0.3581 & 0.6892 & 0.4907 & 13 & 10 \\
\hline 1_U & 4.8 & 0.9189 & 5.7 & 0.9487 & -0.4595 & 0.6459 & 0.2297 & 0.8183 & 10 & 9 \\
\hline $1 \_\mathrm{B}_{\mathrm{W}}$ & 4.3 & 0.4830 & 3.5 & 0.8498 & -0.4595 & 0.6459 & 0.2297 & 0.8183 & 10 & 7 \\
\hline 1_UW & 2.8 & 0.4216 & 3.1 & 1.1005 & -2.7568 & 0.0058 & 2.5271 & 0.0115 & 5 & 4 \\
\hline 1_B $B_{F}$ & 5.7 & 0.6749 & 5.4 & 1.0750 & 0.9189 & 0.3581 & 0.6892 & 0.4907 & 13 & 12 \\
\hline 1_U $\mathrm{U}_{\mathrm{F}}$ & 2.0 & 0.6667 & 1.6 & 0.6992 & -1.3784 & 0.1681 & 1.1487 & 0.2507 & 8 & 6 \\
\hline $1 \_B_{R}$ & 4.4 & 0.8433 & 4.2 & 1.1353 & 0.0000 & 1.0000 & -0.2297 & 0.8183 & 11 & 8 \\
\hline 1_U $\mathrm{U}_{\mathrm{R}}$ & 2.9 & 0.8756 & 2.6 & 0.6992 & -0.9189 & 0.3581 & 0.6892 & 0.4907 & 9 & 6 \\
\hline 2_B $\mathrm{B}_{\mathrm{C}}$ & 3.7 & 1.0593 & 3.9 & 0.5676 & -0.9189 & 0.3581 & 0.6892 & 0.4907 & 9 & 7 \\
\hline 2_U $\mathrm{U}_{\mathrm{C}}$ & 4.8 & 0.7888 & 4.6 & 1.0750 & 1.3784 & 0.1681 & 1.1487 & 0.2507 & 14 & 11 \\
\hline $2 \_B_{W}$ & 5.6 & 0.6992 & 5.5 & 0.9718 & 0.4595 & 0.6459 & 0.2297 & 0.8183 & 12 & 10 \\
\hline $2 \_U_{W}$ & 2.7 & 1.0593 & 2.3 & 0.8233 & -1.3784 & 0.1681 & 1.1487 & 0.2507 & 8 & 7 \\
\hline 2_B $B_{F}$ & 5.1 & 0.5676 & 3.9 & 0.9944 & -1.3784 & 0.1681 & 1.1487 & 0.2507 & 8 & 6 \\
\hline $2 \_U_{F}$ & 3.2 & 0.7888 & 2.5 & 0.7071 & -1.3784 & 0.1681 & 1.1487 & 0.2507 & 8 & 6 \\
\hline 2_B ${ }_{R}$ & 5.2 & 0.6325 & 4.8 & 0.6325 & -0.9189 & 0.3581 & 0.6892 & 0.4907 & 9 & 8 \\
\hline 2_U $U_{R}$ & 3.0 & 0.9428 & 2.3 & 0.8233 & -0.4595 & 0.6459 & 0.2297 & 0.8183 & 10 & 7 \\
\hline 3_B ${ }_{C}$ & 4.5 & 0.5270 & 4.3 & 0.4830 & 0.4595 & 0.6459 & 0.2297 & 0.8183 & 12 & 10 \\
\hline 3_U $\mathrm{U}_{\mathrm{C}}$ & 5.7 & 0.8233 & 5.6 & 1.0750 & 0.0000 & 1.0000 & -0.2297 & 0.8183 & 11 & 9 \\
\hline 3_B $\mathrm{B}_{\mathrm{W}}$ & 5.0 & 1.0541 & 4.9 & 0.8756 & 1.3784 & 0.1681 & 1.1487 & 0.2507 & 14 & 12 \\
\hline 3_U $\mathrm{U}_{\mathrm{W}}$ & 6.0 & 0.9428 & 5.9 & 0.8756 & 0.9189 & 0.3581 & 0.6892 & 0.4907 & 13 & 10 \\
\hline 3_B $B_{F}$ & 5.0 & 0.8165 & 4.3 & 0.8233 & 1.3784 & 0.1681 & 1.1487 & 0.2507 & 14 & 11 \\
\hline 3_U $\mathrm{U}_{\mathrm{F}}$ & 6.4 & 0.9661 & 6.3 & 0.9487 & 0.0000 & 1.0000 & -0.2297 & 0.8183 & 11 & 10 \\
\hline 3_BR & 5.1 & 0.8756 & 4.8 & 0.9189 & -0.9189 & 0.3581 & 0.6892 & 0.4907 & 9 & 7 \\
\hline 3_U $U_{R}$ & 6.2 & 0.9189 & 6.0 & 0.6667 & -0.9189 & 0.3581 & 0.6892 & 0.4907 & 9 & 6 \\
\hline
\end{tabular}


Table 4. Cont.

\begin{tabular}{|c|c|c|c|c|c|c|c|c|c|c|}
\hline Variable & $\operatorname{Mean}_{(C)}$ & $\mathrm{SD}_{(\mathrm{C})}$ & $\operatorname{Mean}_{(\mathrm{B})}$ & $\mathrm{SD}_{(\mathrm{B})}$ & $\mathrm{Z}$ & $p$-Value & Z Adjstd & $p$-Value & No. of Runs & No. of Ties \\
\hline 4_B $\mathrm{C}$ & 4.2 & 0.4216 & 4.1 & 0.3162 & -2.2973 & 0.0216 & 2.0676 & 0.0387 & 6 & 5 \\
\hline $4 \mathrm{U}_{\mathrm{C}}$ & 5.5 & 0.5270 & 5.0 & 1.4142 & 0.4595 & 0.6459 & 0.2297 & 0.8183 & 12 & 10 \\
\hline $4 \mathrm{~B}_{\mathrm{W}}$ & 4.8 & 0.6325 & 4.8 & 0.4216 & 0.0000 & 1.0000 & -0.2297 & 0.8183 & 11 & 8 \\
\hline $4 \_U_{W}$ & 4.3 & 0.8233 & 3.6 & 1.0750 & 0.0000 & 1.0000 & -0.2297 & 0.8183 & 11 & 8 \\
\hline $4 \_\mathrm{B}_{\mathrm{F}}$ & 4.6 & 0.5164 & 4.3 & 0.4830 & -0.4595 & 0.6459 & 0.2297 & 0.8183 & 10 & 9 \\
\hline $4 U_{F}$ & 5.0 & 0.8165 & 4.1 & 0.8756 & -2.7568 & 0.0058 & 2.5271 & 0.0115 & 5 & 3 \\
\hline 4_B ${ }_{\mathrm{R}}$ & 4.7 & 0.6749 & 4.3 & 0.4830 & 0.4595 & 0.6459 & 0.2297 & 0.8183 & 12 & 11 \\
\hline 4_U $\mathrm{U}_{\mathrm{R}}$ & 4.7 & 0.6749 & 3.9 & 0.8756 & -1.8379 & 0.0661 & 1.6081 & 0.1078 & 7 & 4 \\
\hline 5_B $\mathrm{B}_{\mathrm{C}}$ & 5.2 & 0.9189 & 4.4 & 0.6992 & -1.3784 & 0.1681 & 1.1487 & 0.2507 & 8 & 4 \\
\hline 5_U $\mathrm{U}_{\mathrm{C}}$ & 5.4 & 1.1738 & 5.5 & 0.9718 & 1.8379 & 0.0661 & 1.6081 & 0.1078 & 15 & 11 \\
\hline 5_B $\mathrm{B}_{\mathrm{W}}$ & 6.3 & 1.0593 & 6.0 & 0.6667 & 0.9189 & 0.3581 & 0.6892 & 0.4907 & 13 & 10 \\
\hline 5_UW & 5.8 & 1.0328 & 4.2 & 1.0328 & -1.3784 & 0.1681 & 1.1487 & 0.2507 & 8 & 6 \\
\hline 5_B $\mathrm{B}_{\mathrm{F}}$ & 5.2 & 1.2293 & 4.0 & 0.6667 & -1.3784 & 0.1681 & 1.1487 & 0.2507 & 8 & 6 \\
\hline 5_U $U_{F}$ & 6.5 & 0.9718 & 6.2 & 0.4216 & 0.0000 & 1.0000 & -0.2297 & 0.8183 & 11 & 8 \\
\hline 5_B ${ }_{R}$ & 5.9 & 0.9944 & 5.3 & 0.8233 & -0.9189 & 0.3581 & 0.6892 & 0.4907 & 9 & 7 \\
\hline 5_U $U_{R}$ & 5.6 & 1.1738 & 4.3 & 1.0593 & -0.4595 & 0.6459 & 0.2297 & 0.8183 & 10 & 6 \\
\hline 6_B $\mathrm{B}_{\mathrm{C}}$ & 4.6 & 0.5164 & 4.3 & 0.4830 & 0.4595 & 0.6459 & 0.2297 & 0.8183 & 12 & 11 \\
\hline 6_U $\mathrm{U}_{\mathrm{C}}$ & 3.9 & 0.9944 & 3.4 & 0.9661 & -0.4595 & 0.6459 & 0.2297 & 0.8183 & 10 & 6 \\
\hline $6 \_B_{W}$ & 5.3 & 0.6749 & 5.4 & 0.6992 & -0.9189 & 0.3581 & 0.6892 & 0.4907 & 9 & 8 \\
\hline 6_U $\mathrm{U}_{\mathrm{W}}$ & 3.5 & 1.2693 & 2.6 & 0.5164 & -0.9189 & 0.3581 & 0.6892 & 0.4907 & 9 & 6 \\
\hline 6_B $\mathrm{B}_{\mathrm{F}}$ & 4.5 & 0.7071 & 4.0 & 0.4714 & -0.4595 & 0.6459 & 0.2297 & 0.8183 & 10 & 9 \\
\hline 6_U $U_{F}$ & 5.1 & 1.1005 & 3.8 & 0.9189 & -0.4595 & 0.6459 & 0.2297 & 0.8183 & 10 & 8 \\
\hline 6_B $\mathrm{R}$ & 4.8 & 0.4216 & 5.0 & 0.4714 & -0.9189 & 0.3581 & 0.6892 & 0.4907 & 9 & 7 \\
\hline 6_U $\mathrm{U}_{\mathrm{R}}$ & 3.8 & 0.7888 & 3.3 & 0.9487 & 1.3784 & 0.1681 & 1.1487 & 0.2507 & 14 & 11 \\
\hline 7_B & 5.7 & 1.0593 & 5.9 & 0.5676 & 0.9189 & 0.3581 & 0.6892 & 0.4907 & 13 & 10 \\
\hline 7_U & 3.4 & 1.5776 & 2.4 & 0.6992 & 0.4595 & 0.6459 & 0.2297 & 0.8183 & 12 & 8 \\
\hline 7_B $\mathrm{B}_{\mathrm{W}}$ & 4.6 & 1.0750 & 4.1 & 0.5676 & -1.3784 & 0.1681 & 1.1487 & 0.2507 & 8 & 7 \\
\hline 7_UW & 5.6 & 1.4298 & 6.3 & 0.6749 & 0.0000 & 1.0000 & -0.2297 & 0.8183 & 11 & 9 \\
\hline 7_B ${ }_{F}$ & 4.6 & 1.1738 & 4.0 & 0.6667 & 0.9189 & 0.3581 & 0.6892 & 0.4907 & 13 & 10 \\
\hline 7_U & 6.1 & 1.1005 & 5.7 & 1.0593 & -0.4595 & 0.6459 & 0.2297 & 0.8183 & 10 & 5 \\
\hline 7_B ${ }_{R}$ & 4.6 & 1.0750 & 4.9 & 0.9944 & -0.4595 & 0.6459 & 0.2297 & 0.8183 & 10 & 7 \\
\hline 7_U $\mathrm{U}_{\mathrm{R}}$ & 5.0 & 1.0541 & 4.3 & 1.5670 & -0.4595 & 0.6459 & 0.2297 & 0.8183 & 10 & 7 \\
\hline 8_B ${ }_{C}$ & 5.6 & 0.8433 & 5.8 & 0.7888 & -0.9189 & 0.3581 & 0.6892 & 0.4907 & 9 & 8 \\
\hline 8_U $\mathrm{U}_{\mathrm{C}}$ & 2.1 & 0.5676 & 1.7 & 0.4830 & -0.4595 & 0.6459 & 0.2297 & 0.8183 & 10 & 7 \\
\hline $8 \_B_{W}$ & 4.4 & 0.6992 & 4.3 & 0.4830 & -0.9189 & 0.3581 & 0.6892 & 0.4907 & 9 & 8 \\
\hline $8 \_U_{W}$ & 3.5 & 0.8498 & 3.0 & 0.6667 & -1.3784 & 0.1681 & 1.1487 & 0.2507 & 8 & 7 \\
\hline 8_B $B_{F}$ & 4.5 & 0.5270 & 4.2 & 0.4216 & 0.4595 & 0.6459 & 0.2297 & 0.8183 & 12 & 10 \\
\hline 8_U $U_{F}$ & 3.7 & 0.9487 & 3.2 & 0.4216 & -1.8379 & 0.0661 & 1.6081 & 0.1078 & 7 & 6 \\
\hline 8_B ${ }_{R}$ & 4.6 & 0.6992 & 4.9 & 0.7379 & -0.4595 & 0.6459 & 0.2297 & 0.8183 & 10 & 8 \\
\hline 8_U $U_{R}$ & 2.8 & 0.7888 & 2.8 & 0.7888 & 0.4595 & 0.6459 & 0.2297 & 0.8183 & 12 & 8 \\
\hline
\end{tabular}


Table 4. Cont

\begin{tabular}{|c|c|c|c|c|c|c|c|c|c|c|}
\hline Variable & $\operatorname{Mean}_{(\mathrm{C})}$ & $\mathrm{SD}_{(\mathrm{C})}$ & $\operatorname{Mean}_{(B)}$ & $\mathrm{SD}_{(\mathrm{B})}$ & $\mathbf{Z}$ & $p$-Value & Z Adjstd & $p$-Value & No. of Runs & No. of Ties \\
\hline 9_BC & 5.2 & 0.7888 & 5.5 & 0.5270 & 0.0000 & 1.0000 & -0.2297 & 0.8183 & 11 & 9 \\
\hline 9_U & 2.2 & 0.6325 & 2.2 & 0.6325 & 0.9189 & 0.3581 & 0.6892 & 0.4907 & 13 & 10 \\
\hline 9_B $\mathrm{B}_{W}$ & 5.3 & 0.8233 & 5.8 & 0.7888 & 0.4595 & 0.6459 & 0.2297 & 0.8183 & 12 & 9 \\
\hline 9_UW & 2.0 & 0.9428 & 2.0 & 0.4714 & -0.9189 & 0.3581 & 0.6892 & 0.4907 & 9 & 7 \\
\hline 9_B $\mathrm{B}_{\mathrm{F}}$ & 4.4 & 0.9661 & 4.0 & 0.4714 & -0.9189 & 0.3581 & 0.6892 & 0.4907 & 9 & 7 \\
\hline 9_U $U_{F}$ & 4.9 & 1.1972 & 4.1 & 0.8756 & 0.4595 & 0.6459 & 0.2297 & 0.8183 & 12 & 10 \\
\hline 9_B $\mathrm{B}_{\mathrm{R}}$ & 5.4 & 0.8433 & 5.6 & 0.8433 & -1.3784 & 0.1681 & 1.1487 & 0.2507 & 8 & 7 \\
\hline 9_U $\mathrm{U}_{\mathrm{R}}$ & 2.6 & 1.0750 & 2.5 & 1.4337 & -0.4595 & 0.6459 & 0.2297 & 0.8183 & 10 & 8 \\
\hline $10 \_B_{C}$ & 6.6 & 0.5164 & 6.9 & 0.3162 & -0.4595 & 0.6459 & 0.2297 & 0.8183 & 10 & 9 \\
\hline $10 \_U_{C}$ & 5.1 & 1.2867 & 5.6 & 0.5164 & 0.0000 & 1.0000 & -0.2297 & 0.8183 & 11 & 9 \\
\hline 10_B $\mathrm{B}$ & 5.4 & 0.8433 & 5.3 & 0.6749 & -1.8379 & 0.0661 & 1.6081 & 0.1078 & 7 & 6 \\
\hline 10_U $\mathrm{U}_{\mathrm{W}}$ & 6.2 & 1.0328 & 4.8 & 1.1353 & -2.2973 & 0.0216 & 2.0676 & 0.0387 & 6 & 4 \\
\hline $10 \_B_{F}$ & 4.8 & 1.1353 & 3.8 & 0.4216 & -0.4595 & 0.6459 & 0.2297 & 0.8183 & 10 & 7 \\
\hline 10_U $U_{F}$ & 6.4 & 0.6992 & 6.5 & 0.5270 & 0.9189 & 0.3581 & 0.6892 & 0.4907 & 13 & 11 \\
\hline $10 \_B_{R}$ & 5.6 & 0.6992 & 6.2 & 0.7888 & -0.9189 & 0.3581 & 0.6892 & 0.4907 & 9 & 7 \\
\hline 10_U $U_{R}$ & 5.7 & 0.6749 & 4.2 & 1.3166 & -2.2973 & 0.0216 & 2.0676 & 0.0387 & 6 & 2 \\
\hline
\end{tabular}

Marked tests are significant at $p<0.05$.

According to the results only for 5 in 80 analyzed lighting features, the difference between the group means was statistically significant at the level of 0.05 . In $93.75 \%$ of cases, differences in brightness and uniformity perception between the group means were not significant.

3.4. Comparison of Brightness Perception of Computer Image of Illuminated Corridor for Each Solution Separately, between Groups

The convergence in evaluation of brightness perception between the groups was also assessed, for each solution separately. For this purpose, individually for every solution from 1 to 10, the mean plane and corridor brightness perception levels resulting from the questionnaires in groups $B$ and $C$ were ranked in descending order. The ranks, from 1-the highest brightness level to 4-the lowest brightness level, were assigned to the mean brightness levels for each solution. The survey results of the mean brightness perception levels and the assigned ranks are shown in Table 5 for group B and in Table 6 for group C.

Table 5. Survey results and ranking of mean brightness perception levels of computer image of corridor for each solution, in group B.

\begin{tabular}{ccccccccccc}
\hline \multirow{2}{*}{ Parameter } & \multicolumn{10}{c}{ Solution } \\
\cline { 2 - 13 } & $\mathbf{1}$ & $\mathbf{2}$ & $\mathbf{3}$ & $\mathbf{4}$ & $\mathbf{5}$ & $\mathbf{6}$ & $\mathbf{7}$ & $\mathbf{8}$ & $\mathbf{9}$ & $\mathbf{1 0}$ \\
\hline $\mathrm{B}_{\mathrm{F}(\mathrm{B})}$ & 5.40 & 3.90 & 4.30 & 4.30 & 4.00 & 4.00 & 4.00 & 4.20 & 4.00 & 3.80 \\
\hline $\mathrm{RB}_{\mathrm{F}(\mathrm{B})}$ & 1 & $3-4$ & $3-4$ & $2-3$ & 4 & 4 & 4 & 4 & 4 & 4 \\
\hline $\mathrm{B}_{\mathrm{W}(\mathrm{B})}$ & 3.50 & 5.50 & 4.90 & 4.80 & 6.00 & 5.40 & 4.10 & 4.30 & 5.80 & 5.30 \\
\hline $\mathrm{RB}_{\mathrm{W}(\mathrm{B})}$ & 3 & 1 & 1 & 1 & 1 & 1 & 3 & 3 & 1 & 3 \\
\hline $\mathrm{B}_{\mathrm{C}(\mathrm{B})}$ & 3.00 & 3.90 & 4.30 & 4.10 & 4.40 & 4.30 & 5.90 & 5.80 & 5.50 & 6.90 \\
\hline $\mathrm{RB}_{\mathrm{C}(\mathrm{B})}$ & 4 & $3-4$ & $3-4$ & 4 & 3 & 3 & 1 & 1 & 3 & 1 \\
\hline $\mathrm{B}_{\mathrm{G}(\mathrm{B})}$ & 4.20 & 4.80 & 4.80 & 4.30 & 5.30 & 5.00 & 4.90 & 4.90 & 5.60 & 6.20 \\
\hline $\mathrm{RB}_{\mathrm{G}(\mathrm{B})}$ & 2 & 2 & 2 & $2-3$ & 2 & 2 & 2 & 2 & 2 & 2 \\
\hline
\end{tabular}

Orange-marked cells indicate the cases of the highest mean brightness perception for a given solution, in group $\mathrm{B}$ Blue-marked cells indicate the cases of the lowest mean brightness perception for a given solution, in group B. 
Table 6. Survey results and ranking of mean brightness perception levels of computer image of corridor for each solution, in group C.

\begin{tabular}{ccccccccccc}
\hline \multirow{2}{*}{ Parameter } & \multicolumn{10}{c}{ Solution } \\
\cline { 2 - 13 } & $\mathbf{1}$ & $\mathbf{2}$ & $\mathbf{3}$ & $\mathbf{4}$ & $\mathbf{5}$ & $\mathbf{6}$ & $\mathbf{7}$ & $\mathbf{8}$ & $\mathbf{9}$ & $\mathbf{1 0}$ \\
\hline $\mathrm{B}_{\mathrm{F}(\mathrm{C})}$ & 5.70 & 5.10 & 5.00 & 4.60 & 5.20 & 4.50 & 4.60 & 4.50 & 4.40 & 4.80 \\
\hline $\mathrm{RB}_{\mathrm{F}(\mathrm{C})}$ & 1 & 3 & $2-3$ & 3 & $3-4$ & 4 & $2-4$ & 3 & 4 & 4 \\
\hline $\mathrm{B}_{\mathrm{W}(\mathrm{C})}$ & 4.30 & 5.60 & 5.00 & 4.80 & 6.30 & 5.30 & 4.60 & 4.40 & 5.30 & 5.40 \\
\hline $\mathrm{RB}_{\mathrm{W}(\mathrm{C})}$ & 3 & 1 & $2-3$ & 1 & 1 & 1 & $2-4$ & 4 & 2 & 3 \\
\hline $\mathrm{B}_{\mathrm{C}(\mathrm{C})}$ & 3.20 & 3.70 & 4.50 & 4.20 & 5.20 & 4.60 & 5.70 & 5.60 & 5.20 & 6.60 \\
\hline $\mathrm{RB}_{\mathrm{C}(\mathrm{C})}$ & 4 & 4 & 4 & 4 & $3-4$ & 3 & 1 & 1 & 3 & 1 \\
\hline $\mathrm{B}_{\mathrm{G}(\mathrm{C})}$ & 4.40 & 5.20 & 5.10 & 4.70 & 5.90 & 4.80 & 4.60 & 4.60 & 5.40 & 5.60 \\
\hline $\mathrm{RB}_{\mathrm{G}(\mathrm{C})}$ & 2 & 2 & 1 & 2 & 2 & 2 & $2-4$ & 2 & 1 & 2 \\
\hline $\mathrm{Oryyyyyyyyy}$
\end{tabular}

Orange-marked cells indicate the cases of the highest mean brightness perception for a given solution, in group $\mathrm{C}$. Blue-marked cells indicate the cases of the lowest mean brightness perception for a given solution, in group $\mathrm{C}$. Green marked cells indicate discrepancy in sequence of brightness impressions in relation to group B.

In Table 5, the presented symbols are as follows: The mean brightness perception for: Floor $\mathrm{B}_{\mathrm{F}(\mathrm{B})}$, walls $\mathrm{B}_{\mathrm{W}(\mathrm{B})}$, ceiling $\mathrm{B}_{\mathrm{C}(\mathrm{B})}$, and corridor $\mathrm{B}_{\mathrm{G}(\mathrm{B})}$, and the assigned ranks in $\mathrm{B}$ group for: Floor $\mathrm{RB}_{\mathrm{F}(\mathrm{B})}$, walls $\mathrm{RB}_{\mathrm{W}(\mathrm{B})}$, ceiling $\mathrm{RB}_{\mathrm{C}(\mathrm{B})}$, and corridor $\mathrm{RB}_{\mathrm{G}(\mathrm{B})}$. In Table 6, the symbols are as follows: The mean brightness perception for: Floor $\mathrm{B}_{\mathrm{F}(\mathrm{C})}$, walls $\mathrm{B}_{\mathrm{W}(\mathrm{C})}$, ceiling $\mathrm{B}_{\mathrm{C}(\mathrm{C})}$, and corridor $\mathrm{B}_{\mathrm{G}(\mathrm{C})}$, and the assigned ranks in $\mathrm{C}$ group for: Floor $\mathrm{RB}_{\mathrm{F}(\mathrm{C})}$, walls $R B_{W(C)}$, ceiling $R_{C}(C)$, and corridor $R_{G(C)}$.

For seven situations, there is the convergence of sequence of brightness perception assessment in groups B and C. The discrepancies concern situations 3, 8, and 9.

In situation 3, in group $C$ it was assessed that the entire corridor was characterized by the highest brightness (5.10), while in group $B$ the highest brightness was assigned to the walls (4.90). It should be noted that for this situation the differences between the brightness perception between the planes and the corridor were low and amounted to a maximum of 0.6 in every group.

In situation 8 , in group $C$ it was assessed that the walls were characterized by the lowest brightness (4.40), and in group B it was estimated that the floor was characterized by the lowest brightness (4.20). However, it should be noted that the difference between the perception of the brightness of the walls and the floor was only 0.1 in each group.

In situation 9, in group $C$ it was assessed that the entire corridor was characterized by the highest brightness (5.40) while in group B the highest brightness (5.80) was assigned to the walls. Again, it should be noted that for this situation the differences between the brightness perception for the walls, ceiling and the entire corridor were low and amounted to 0.3 in group B and 0.2 in group C maximum.

\subsection{Comparison of Uniformity Perception of Computer Image of Illuminated Corridor for Each Solution Separately, between Groups}

The convergence of the uniformity perception between the groups was also assessed. For this purpose, individually for each solution from 1 to 10 , the mean plane and corridor uniformity perception levels resulting from the surveys in groups B and C were ranked in descending order. The ranks, from 1-the highest uniformity level to 4 -the lowest uniformity level, were assigned to the mean uniformity levels for each solution. The survey results of the mean uniformity perception levels and the assigned ranks are shown in Table 7 for group B and in Table 8 for group C. In Table 7, the symbols are as follows: The mean uniformity perception for: Floor $\mathrm{U}_{\mathrm{F}(\mathrm{B})}$, walls $\mathrm{U}_{\mathrm{W}(\mathrm{B})}$, ceiling $\mathrm{U}_{\mathrm{C}(\mathrm{B})}$, and corridor $\mathrm{U}_{\mathrm{G}(\mathrm{B})}$, and the assigned ranks in group $\mathrm{B}$ for: Floor $\mathrm{RU}_{\mathrm{F}(\mathrm{B})}$, walls $\mathrm{RU}_{\mathrm{W}(\mathrm{B})}$, ceiling $\mathrm{RU}_{\mathrm{C}(\mathrm{B})}$, and corridor $\mathrm{RU}_{\mathrm{G}(\mathrm{B})}$. In Table 8, the symbols are as follows: The mean uniformity perception for: Floor $\mathrm{U}_{\mathrm{F}(\mathrm{C})}$, walls $\mathrm{U}_{\mathrm{W}(\mathrm{C})}$, ceiling $\mathrm{U}_{\mathrm{C}(\mathrm{C})}$, and corridor $\mathrm{U}_{\mathrm{G}(\mathrm{C})}$, and the assigned ranks $\mathrm{C}$ group for: Floor $\mathrm{RU}_{\mathrm{F}(\mathrm{C})}$, walls $\mathrm{RU}_{\mathrm{W}(\mathrm{C})}$, ceiling $\mathrm{RU}_{\mathrm{C}(\mathrm{C})}$, and corridor $\mathrm{RU}_{\mathrm{G}(\mathrm{C})}$. 
Table 7. Survey results and ranking of mean uniformity levels of computer image of corridor for each solution, in group B.

\begin{tabular}{ccccccccccc}
\hline & \multicolumn{10}{c}{ Solution } \\
\cline { 2 - 14 } Parameter & $\mathbf{1}$ & $\mathbf{2}$ & $\mathbf{3}$ & $\mathbf{4}$ & $\mathbf{5}$ & $\mathbf{6}$ & $\mathbf{7}$ & $\mathbf{8}$ & $\mathbf{9}$ & $\mathbf{1 0}$ \\
\hline $\mathrm{U}_{\mathrm{F}(\mathrm{B})}$ & 1.60 & 2.50 & 6.30 & 4.10 & 6.20 & 3.80 & 5.70 & 3.20 & 4.10 & 6.50 \\
\hline $\mathrm{RU}_{\mathrm{F}(\mathrm{B})}$ & 4 & 2 & 1 & 2 & 1 & 1 & 2 & 1 & 1 & 1 \\
\hline $\mathrm{U}_{\mathrm{W}(\mathrm{B})}$ & 3.10 & 2.30 & 5.90 & 3.60 & 4.20 & 2.60 & 6.30 & 3.00 & 2.00 & 4.80 \\
\hline $\mathrm{RU}_{\mathrm{W}(\mathrm{B})}$ & 2 & $3-4$ & 3 & 4 & 4 & 4 & 1 & 2 & 4 & 3 \\
\hline $\mathrm{U}_{\mathrm{C}(\mathrm{B})}$ & 5.70 & 4.60 & 5.60 & 5.00 & 5.50 & 3.40 & 2.40 & 1.70 & 2.20 & 5.60 \\
\hline $\mathrm{RU}_{\mathrm{C}(\mathrm{B})}$ & 1 & 1 & 4 & 1 & 2 & 2 & 4 & 4 & 3 & 2 \\
\hline $\mathrm{U}_{\mathrm{G}(\mathrm{B})}$ & 2.60 & 2.30 & 6.00 & 3.90 & 4.30 & 3.30 & 4.30 & 2.80 & 2.50 & 4.20 \\
\hline $\mathrm{RU}_{\mathrm{G}(\mathrm{B})}$ & 3 & $3-4$ & 2 & 3 & 3 & 3 & 3 & 3 & 2 & 4 \\
\hline
\end{tabular}

Orange-marked cells indicate the cases of the highest mean uniformity perception for a given solution. Bluemarked cells indicate the cases of the lowest mean uniformity perception for a given solution.

Table 8. Survey results and ranking of mean uniformity levels of computer image of corridor for each solution, in group $\mathrm{C}$.

\begin{tabular}{ccccccccccc}
\hline \multirow{2}{*}{ Parameter } & \multicolumn{10}{c}{ Solution } \\
\cline { 2 - 13 } & $\mathbf{1}$ & $\mathbf{2}$ & $\mathbf{3}$ & $\mathbf{4}$ & $\mathbf{5}$ & $\mathbf{6}$ & $\mathbf{7}$ & $\mathbf{8}$ & $\mathbf{9}$ & $\mathbf{1 0}$ \\
\hline $\mathrm{U}_{\mathrm{F}(\mathrm{C})}$ & 2.00 & 3.20 & 6.40 & 5.00 & 6.50 & 5.10 & 6.10 & 3.70 & 4.90 & 6.40 \\
\hline $\mathrm{RU}_{\mathrm{F}(\mathrm{C})}$ & 4 & 2 & 1 & 2 & 1 & 1 & 1 & 1 & 1 & 1 \\
\hline $\mathrm{U}_{\mathrm{W}(\mathrm{C})}$ & 2.80 & 2.70 & 6.00 & 4.30 & 5.80 & 3.50 & 5.60 & 3.50 & 2.00 & 6.20 \\
\hline $\mathrm{RU}_{\mathrm{W}(\mathrm{C})}$ & 3 & 4 & 3 & 4 & 2 & 4 & 2 & 2 & 4 & 2 \\
\hline $\mathrm{U}_{\mathrm{C}(\mathrm{C})}$ & 4.80 & 4.80 & 5.70 & 5.50 & 5.40 & 3.90 & 3.40 & 2.10 & 2.20 & 5.10 \\
\hline $\mathrm{RU}_{\mathrm{C}(\mathrm{C})}$ & 1 & 1 & 4 & 1 & 4 & 2 & 4 & 4 & 3 & 4 \\
\hline $\mathrm{U}_{\mathrm{G}(\mathrm{C})}$ & 2.90 & 3.00 & 6.20 & 4.70 & 5.60 & 3.80 & 5.00 & 2.80 & 2.60 & 5.70 \\
\hline $\mathrm{RU}_{\mathrm{G}(\mathrm{C})}$ & 2 & 3 & 2 & 3 & 3 & 3 & 3 & 3 & 2 & 3 \\
\hline $\mathrm{O}$
\end{tabular}

Orange-marked cells indicate the cases of the highest mean uniformity perception for a given solution. Bluemarked cells indicate the cases of the lowest mean uniformity perception for a given solution. Green marked cells indicate discrepancy in sequence of uniformity perception impressions in relation to group B.

For six situations, there is the convergence of sequence of the uniformity perception assessment in groups B and C. The discrepancies concern situations 1, 5, 7, and 10.

In situation 1, in group C the entire corridor uniformity was rated higher (2.90), and in group B the wall uniformity was rated higher (3.10). It should be noted that the differences between the impressions on uniformity of the walls and entire corridor were low and amounted to 0.5 in group $B$ and 0.1 in group $C$.

In situation 5, in group $C$ the lowest perceived uniformity (5.40) was assigned to the ceiling while in group B the lowest perceived uniformity (4.20) was assigned to the walls. In group B it was assessed that the perceived ceiling uniformity was high (in relation to the floor and the entire interior). The differences in these impressions can be seen in the interpretation of the ceiling uniformity by the respondents. The assessment made by group $B$ that the ceiling uniformity is high (higher of 1.30 than the wall uniformity) can suggest that the ceiling illumination itself was assessed without clearly bright luminaires. However, in group $C$, the ceiling and wall uniformity was assessed in a similar way, which may suggest that while evaluating the ceiling uniformity, the bright contrasting luminaires were taken into account.

In situation 7, in group $C$ the highest perceived uniformity (6.10) was assigned to the floor while in group B the highest perceived uniformity (6.30) was assigned to the walls. It is difficult to unequivocally settle the discrepancy of these assessments. However, it should be noted that in each group the perceived uniformity of the illuminated floor and walls was rated high. Additionally, the differences between the impressions on the floor and wall uniformity were not high and amounted to 0.6 for group B and 0.5 for group C.

In situation 10, in group $C$ the lowest perceived uniformity (5.10) was assigned to the ceiling while in group B the lowest perceived uniformity (4.20) was assigned to the entire 
corridor, but the low one (4.80) was also assigned to the walls. In this situation, it is difficult to unequivocally settle the discrepancy of these assessments.

\section{Conclusions}

The use of various luminous intensity distributions and layouts of luminaires is an effective way of creating the luminance distribution in interior lighting. This applies to the levels and uniformity of illuminance and luminance on the individual planes of the interior as well as the relative illuminance and luminance in the interior. Higher levels of mean illuminances on the ceiling and walls led to a reduction in utilization factor and, consequently, to an increase in lighting power density in the analyzed corridor.

Individual differences in the assessment of brightness and uniformity perception of the lit corridor images presented on the computer screens under various surrounding conditions are significant. However, the high convergence of brightness and uniformity perception of the lit corridor image for the consecutive lighting situations was demonstrated between the mean evaluations for the groups. The result of the non-parametric WaldWolfowitz test showed that in $93.75 \%$ cases differences in brightness and uniformity perception between the groups were not significant. When using the ranking, the high convergence of brightness and uniformity perception of the corridor image for the same lighting solutions was also demonstrated between the mean assessments for the groups.

The case study presented in this article was based on the analysis of ten lighting solutions in a simple corridor. Undoubtedly, this interesting problem requires further research to generalize the results.

Author Contributions: Conceptualization, P.P.; methodology, P.P. and R.K.; software, P.P. and R.K.; validation, P.P. and R.K.; formal analysis, P.P.; investigation, P.P. and R.K.; resources, P.P. and R.K.; data curation, P.P., R.K.; writing-original draft preparation, P.P.; writing-review and editing, P.P. and R.K.; visualization, P.P. and R.K.; supervision, P.P. Both authors have read and agreed to the published version of the manuscript.

Funding: This research received no external funding.

Institutional Review Board Statement: Not applicable.

Informed Consent Statement: Informed consent was obtained from all subjects involved in the study.

Data Availability Statement: The data presented in this study are available on request from the corresponding author.

Acknowledgments: Article Preparation Charge was covered by the Electrical Power Engineering Institute at The Warsaw University of Technology and the Open Access Charge was covered by the IDUB program at the Warsaw University of Technology.

Conflicts of Interest: The authors declare no conflict of interest.

\section{Abbreviations}

Required or Calculated Quantities

$\mathrm{E}_{\mathrm{F}} \quad$ the mean illuminance of the floor

$\mathrm{L}_{\mathrm{F}} \quad$ the mean luminance of the floor

$\mathrm{U}_{\mathrm{FMIN}}$ the uniformity of illuminance/luminance of the floor

$\mathrm{E}_{\mathrm{W}}$ the mean illuminance of the walls

$\mathrm{L}_{\mathrm{W}} \quad$ the mean luminance of the walls

$\mathrm{U}_{\text {WMIN }}$ the uniformity of illuminance/luminance of the walls

$\mathrm{E}_{\mathrm{C}} \quad$ the mean illuminance of the ceiling

$\mathrm{L}_{\mathrm{C}}$ the mean luminance of the ceiling 
$\mathrm{U}_{\mathrm{CMIN}}$ the uniformity of illuminance/luminance of the ceiling

$\mathrm{L}_{\mathrm{R}} \quad$ the mean luminance of the corridor (the weighted average relative to the surface areas of the interior planes)

$\mathrm{E}_{\mathrm{C}} / \mathrm{E}_{\mathrm{F}} \quad$ ceiling illuminance ratio

$\mathrm{E}_{\mathrm{W}} / \mathrm{E}_{\mathrm{F}} \quad$ wall illuminance ratio

UF the utilization factor

PD the installed power density of lighting in the interior

Measured Quantities, Perception Parameters and Ranks

$\mathrm{L}_{\mathrm{FM}}$ the mean luminance of part of the floor in the corridor displayed on the screen

$\mathrm{L}_{W M}$ the mean luminance of part of the walls in the corridor displayed on the screen

$\mathrm{L}_{\mathrm{CM}}$ the mean luminance of part of the ceiling in the corridor displayed on the screen

$\mathrm{L}_{\mathrm{RM}} \quad$ the mean luminance of part of the entire corridor displayed on the screen

$\mathrm{B}_{\mathrm{F}(\mathrm{B})} \quad$ the mean brightness perception in $\mathrm{B}$ group for floor

$\mathrm{B}_{\mathrm{W}(\mathrm{B})} \quad$ the mean brightness perception in $\mathrm{B}$ group for walls

$\mathrm{B}_{\mathrm{C}(\mathrm{B})} \quad$ the mean brightness perception in $\mathrm{B}$ group for ceiling

$\mathrm{B}_{\mathrm{G}(\mathrm{B})} \quad$ the mean brightness perception in $\mathrm{B}$ group for corridor

$\mathrm{B}_{\mathrm{F}(\mathrm{C})} \quad$ the mean brightness perception in $\mathrm{C}$ group for floor

$\mathrm{B}_{\mathrm{W}(\mathrm{C})}$ the mean brightness perception in $\mathrm{C}$ group for walls

$\mathrm{B}_{\mathrm{C}(\mathrm{C})} \quad$ the mean brightness perception in $\mathrm{C}$ group for ceiling

$\mathrm{B}_{\mathrm{G}(\mathrm{C})}$ the mean brightness perception in $\mathrm{C}$ group for corridor

$\mathrm{RB}_{\mathrm{F}(\mathrm{B})}$ the assigned ranks for the mean brightness perception in $\mathrm{B}$ group for floor

$\mathrm{RB}_{\mathrm{W}(\mathrm{B})}$ the assigned ranks for the mean brightness perception in $\mathrm{B}$ group for walls

$\mathrm{RB}_{\mathrm{C}(\mathrm{B})}$ the assigned ranks for the mean brightness perception in $\mathrm{B}$ group for ceiling

$\mathrm{RB}_{\mathrm{G}(\mathrm{B})}$ the assigned ranks for the mean brightness perception in $\mathrm{B}$ group for corridor

$\mathrm{RB}_{\mathrm{F}(\mathrm{C})}$ the assigned ranks for the mean brightness perception in $\mathrm{C}$ group for floor

$\mathrm{RB}_{\mathrm{W}(\mathrm{C})}$ the assigned ranks for the mean brightness perception in $\mathrm{C}$ group for walls

$\mathrm{RB}_{\mathrm{C}(\mathrm{C})}$ the assigned ranks for the mean brightness perception in $\mathrm{C}$ group for ceiling

$\mathrm{RB}_{\mathrm{G}(\mathrm{C})}$ the assigned ranks for the mean brightness perception in $\mathrm{C}$ group for corridor

$\mathrm{U}_{\mathrm{F}(\mathrm{B})}$ the mean uniformity perception in $\mathrm{B}$ group for floor

$\mathrm{U}_{\mathrm{W}(\mathrm{B})} \quad$ the mean uniformity perception in B group for walls

$\mathrm{U}_{\mathrm{C}(\mathrm{B})} \quad$ the mean uniformity perception in $\mathrm{B}$ group for ceiling

$\mathrm{U}_{\mathrm{G}(\mathrm{B})}$ the mean uniformity perception in $\mathrm{B}$ group for corridor

$\mathrm{U}_{\mathrm{F}(\mathrm{C})}$ the mean uniformity perception in $\mathrm{C}$ group for floor

$\mathrm{U}_{\mathrm{W}(\mathrm{C})}$ the mean uniformity perception in C group for walls

$\mathrm{U}_{\mathrm{C}(\mathrm{C})}$ the mean uniformity perception in $\mathrm{C}$ group for ceiling

$\mathrm{U}_{\mathrm{G}(\mathrm{C})}$ the mean uniformity perception in $\mathrm{C}$ group for corridor

\section{References}

1. Leccese, F.; Salvadori, G.; Rocca, M.; Buratti, C.; Belloni, E. A method to assess lighting quality in educational rooms using analytic hierarchy process. Build. Environ. 2020, 168, 106501. [CrossRef]

2. Asojo, A.O.; Bae, S.; Martin, C.S. Post-occupancy Evaluation Study of the Impact of Daylighting and Electric Lighting in the Workplace. LEUKOS J. Illum. Eng. Soc. N. Am. 2020, 16, 239-250. [CrossRef]

3. Safranek, S.; Collier, J.M.; Wilkerson, A.; Davis, R.G. Energy impact of human health and wellness lighting recommendations for office and classroom applications. Energy Build. 2020, 226, 110365. [CrossRef]

4. Pracki, P.; Dziedzicki, M.; Komorzycka, P. Ceiling and wall illumination, utilance, and power in interior lighting. Energies 2020, 13, 4744. [CrossRef]

5. Leoto, R.; Lizarralde, G. Challenges in evaluating strategies for reducing a building's environmental impact through Integrated Design. Build. Environ. 2019, 155, 34-46. [CrossRef]

6. de Souza, D.F.; da Silva, P.P.F.; Fontenele, L.F.A.; Barbosa, G.D.; de Oliveira Jesus, M. Efficiency, quality, and environmental impacts: A comparative study of residential artificial lighting. Energy Rep. 2019, 5, 409-424. [CrossRef]

7. Mohammadalizadehkorde, M.; Weaver, R. Quantifying potential savings from sustainable energy projects at a large public university: An energy efficiency assessment for texas state university. Sustain. Energy Technol. Assess. 2020, 37, 100570. [CrossRef]

8. Patiño-Cambeiro, F.; Armesto, J.; Bastos, G.; Prieto-López, J.I.; Patiño-Barbeito, F. Economic appraisal of energy efficiency renovations in tertiary buildings. Sustain. Cities Soc. 2019, 47, 101503. [CrossRef]

9. Rea, M.S.; Mou, X.; Bullough, J.D. Scene brightness of illuminated interiors. Light. Res. Technol. 2015, 48, 823-831. [CrossRef]

10. Feltrin, F.; Leccese, F.; Hanselaer, P.; Smet, K.A.G. Impact of Illumination Correlated Color Temperature, Background Lightness, and Painting Color Content on Color Appearance and Appreciation of Paintings. LEUKOS J. Illum. Eng. Soc. N. Am. 2020, 16, 25-44. [CrossRef] 
11. Veitch, J.A.; Newsham, G.R.; Boyce, P.R.; Jones, C.C. Lighting appraisal, well-being and performance in open-plan offices: A linked mechanisms approach. Light. Res. Technol. 2008, 40, 133-148. [CrossRef]

12. Stokkermans, M.; Vogels, I.; de Kort, Y.; Heynderickx, I. A Comparison of Methodologies to Investigate the Influence of Light on the Atmosphere of a Space. LEUKOS J. Illum. Eng. Soc. N. Am. 2018, 14, 167-191. [CrossRef]

13. Moscoso, C.; Matusiak, B. Aesthetic perception of a small office with different daylighting systems. Indoor Built Environ. 2017, 27. [CrossRef]

14. Ulusoy, B.; Olguntürk, N.; Aslanoğlu, R. Colour semantics in residential interior architecture on different interior types. Color. Res. Appl. 2020, 45, 941-952. [CrossRef]

15. Custers, P.J.M.; De Kort, Y.A.W.; Ijsselsteijn, W.A.; De Kruiff, M.E. Lighting in retail environments: Atmosphere perception in the real world. Light. Res. Technol. 2010, 42, 331-343. [CrossRef]

16. Castilla, N.; Llinares, C.; Bisegna, F.; Blanca-Giménez, V. Emotional evaluation of lighting in university classrooms: A preliminary study. Front. Archit. Res. 2018, 7, 600-609. [CrossRef]

17. Houser, K.W.; Tiller, D.K.; Bernecker, C.A.; Mistrick, R.G. The subjective response to linear fluorescent direct/indirect lighting systems. Light. Res. Technol. 2002, 34, 243-260. [CrossRef]

18. Bellia, L.; Fragliasso, F.; Stefanizzi, E. Effects of light source spectrum and background colour on the perception of paintings. Light. Res. Technol. 2020, 52, 36-63. [CrossRef]

19. Wei, M.; Houser, K.W. Systematic Changes in Gamut Size Affect Color Preference. LEUKOS J. Illum. Eng. Soc. N. Am. 2017, 13, 23-32. [CrossRef]

20. Tang, X.; Teunissen, C. The appreciation of LED-based white light sources by Dutch and Chinese people in three application areas. Light. Res. Technol. 2019, 51, 353-372. [CrossRef]

21. Yildirim, K.; Çağatay, K.; Ayalp, N. Effect of wall colour on the perception of classrooms. Indoor Built Environ. 2014, 24. [CrossRef]

22. Krupinski, R. Virtual reality system and scientific visualisation for smart designing and evaluating of lighting. Energies 2020, 13, 5518. [CrossRef]

23. Moscoso, C.; Matusiak, B.; Svensson, U.P.; Orleanski, K. Analysis of stereoscopic images as a new method for daylighting studies. ACM Trans. Appl. Percept. 2015, 11,1-13. [CrossRef]

24. Chamilothori, K.; Wienold, J.; Andersen, M. Adequacy of Immersive Virtual Reality for the Perception of Daylit Spaces: Comparison of Real and Virtual Environments. LEUKOS J. Illum. Eng. Soc. N. Am. 2019, 15, 203-226. [CrossRef]

25. Mahdavi, A.; Eissa, H. Subjective evaluation of architectural lighting via computationally rendered images. J. Illum. Eng. Soc. 2002, 31, 11-20. [CrossRef]

26. Flynn, J.; Hendrick, C.; Spencer, T.; Martyniuk, O. A Guide to Methodology Procedures for Measuring Subjective Impressions in Lighting. J. Illum. Eng. Soc. 2013, 8, 95-110. [CrossRef]

27. Newsham, G.R.; Cetegen, D.; Veitch, J.A.; Whitehead, L. Comparing lighting quality evaluations of real scenes with those from high dynamic range and conventional images. ACM Trans. Appl. Percept. 2010, 7. [CrossRef]

28. Hendrick, C.; Martyniuk, O.; Spencer, T.J.; Flynn, J.E. Procedures for Investigating the Effect of Light on Impression: Simulation of a Real Space by Slides. Environ. Behav. 1977, 9, 491-510. [CrossRef]

29. Villa, C.; Labayrade, R. Multi-objective optimisation of lighting installations taking into account user preferences-A pilot study. Light. Res. Technol. 2013, 45. [CrossRef]

30. European Standard EN 12464-1:2011. Light and Lighting_Lighting of Work Places_Part 1: Interior Work Places; CEN: Brussels, Belgium, 2011.

31. Fotios, S. Using Category Rating to Evaluate the Lit Environment: Is a Meaningful Opinion Captured? LEUKOS J. Illum. Eng. Soc. N. Am. 2019, 15, 127-142. [CrossRef] 